Aus der Klinik für Neurologie

(Prof. Dr. med. M. Bähr)

Der Medizinischen Fakultät der Universität Göttingen

\title{
Untersuchungen zum Inflammasom bei proinflammatorischem Zellstress des Muskels in vitro und in vivo
}

\section{INAUGURAL-DISSERTATION}

\author{
zur Erlangung des Doktorgrades \\ der Medizinischen Fakultät der \\ Georg-August-Universität zu Göttingen
}

vorgelegt von

Imke Bertram

aus Bad Gandersheim

Göttingen 2020 
Dekan:

Referent/in:

Ko-Referent/in:

Drittreferent/in:
Prof. Dr. W. Brück

Prof. Dr. med. J. Schmidt

PD Dr. Fred Lühder

Prof. Dr. mult. Thomas Meyer

Datum der mündlichen Prüfung: $\quad 29.07 .2021$ 
Hiermit erkläre ich, die Dissertation mit dem Titel „Untersuchungen zum Inflammasom bei proinflammatorischem Zellstress des Muskels in vitro und in vivo" eigenständig angefertigt und keine anderen als die von mir angegebenen Hilfsmittel verwendet zu haben.

Göttingen, den 12.11.2020 


\section{Inhaltsverzeichnis}

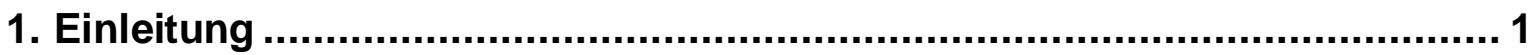

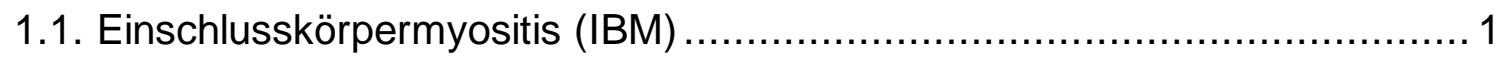

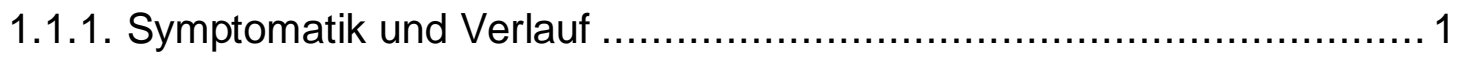

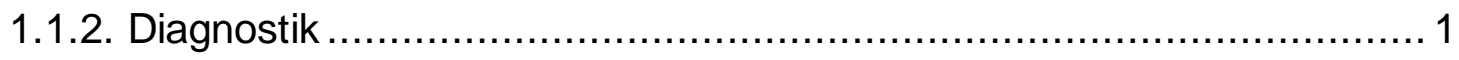

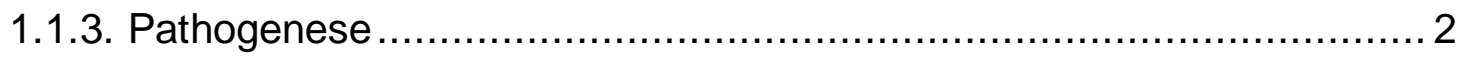

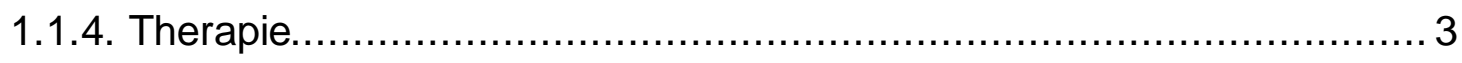

1.2. Myositiden und Myopathien im Vergleich .................................... 3

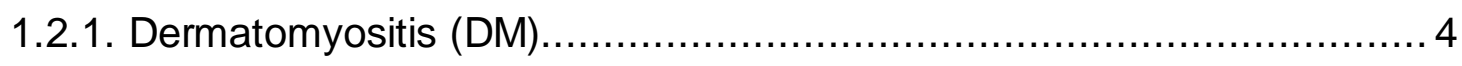

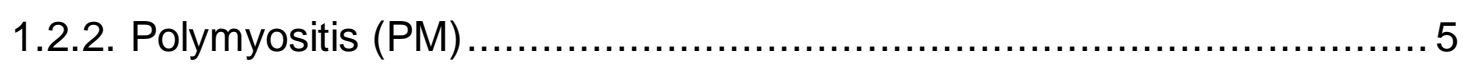

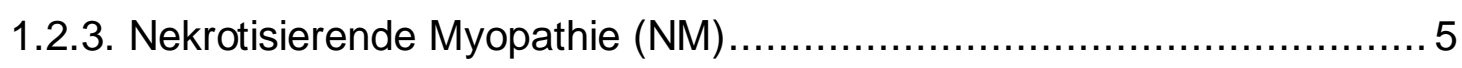

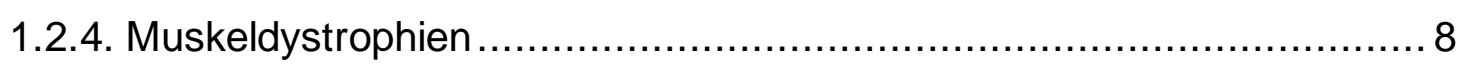

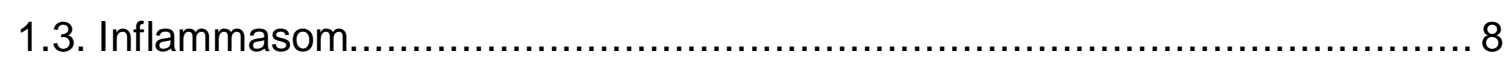

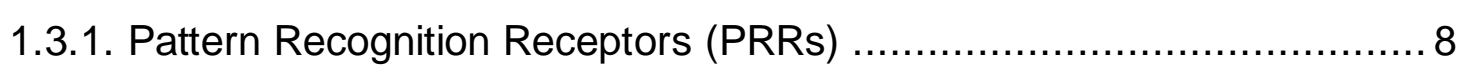

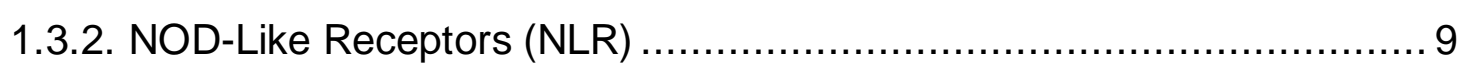

1.3.3. NOD-Like Receptor Protein 3 (NLRP3) ................................ 10

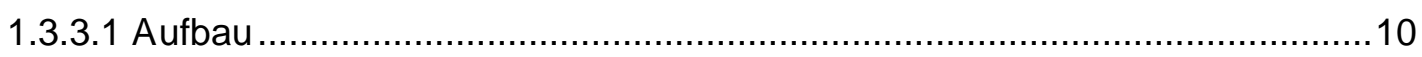

1.3.3.2. Aktivierung und klinische Bedeutung …........................................... 10

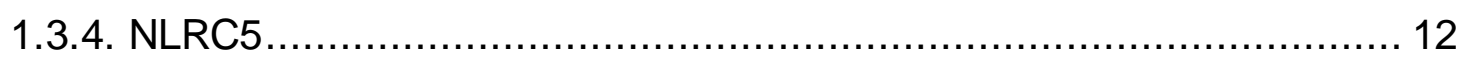

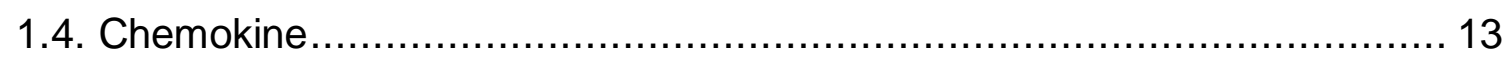

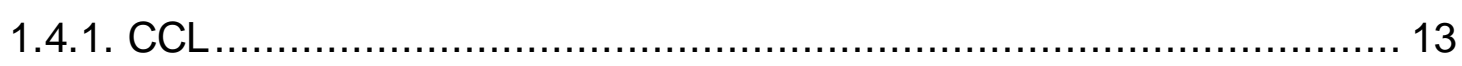

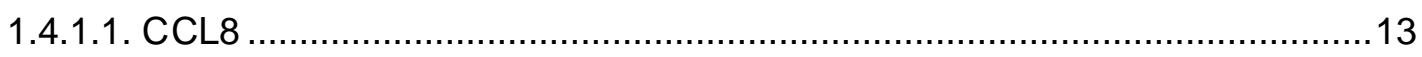

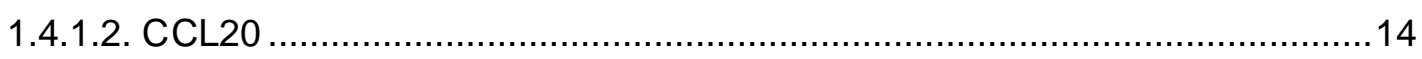

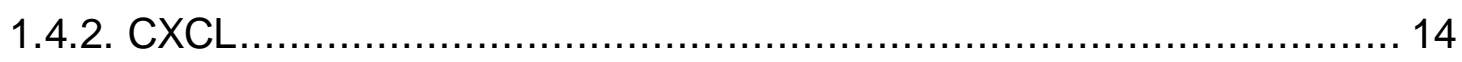

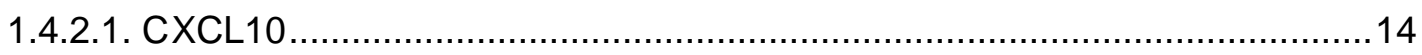

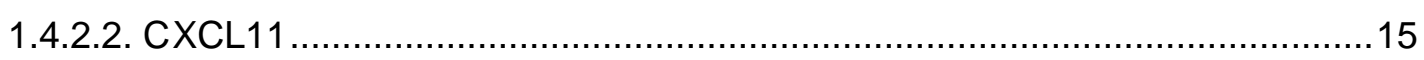

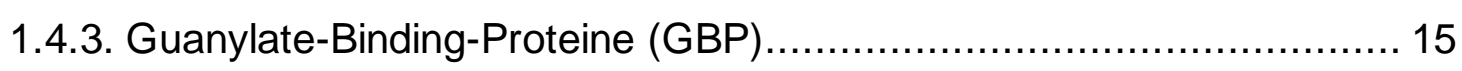

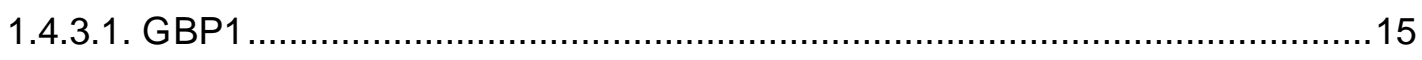

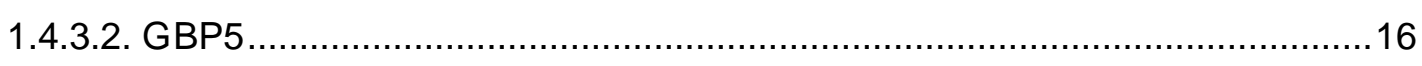

1.5. Zellkulturmodell für chronische Inflammation in Muskelzellen ................. 16

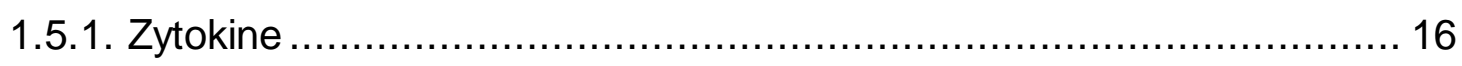

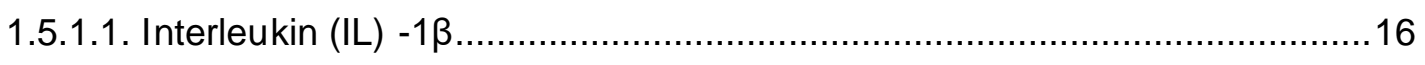

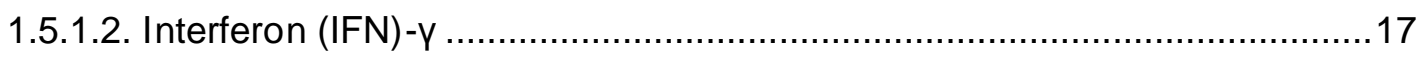

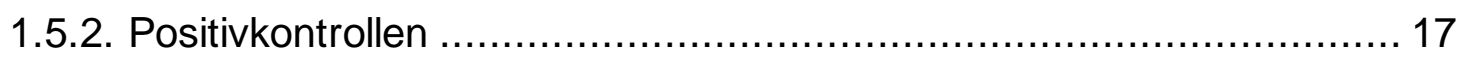

1.5.2.1. Immunzytochemische Positivkontrolle der Zytokinstimulation durch MHC-IHochregulation. 


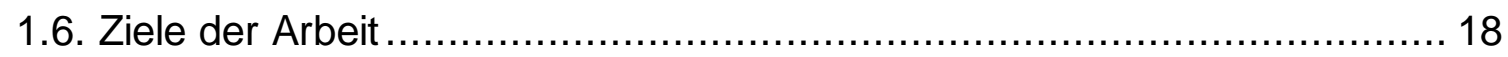

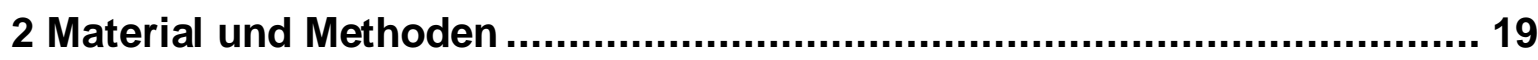

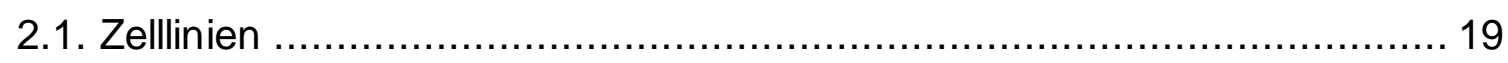

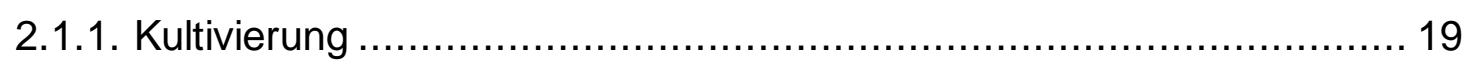

2.1.2. Kultivierung in Chamberslides/6-well-Platten .................................. 20

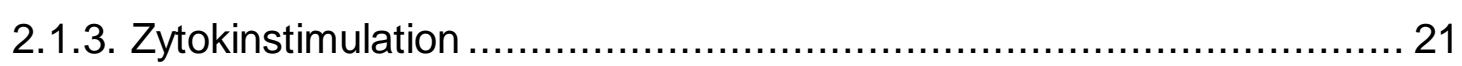

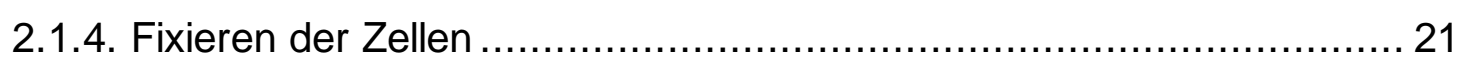

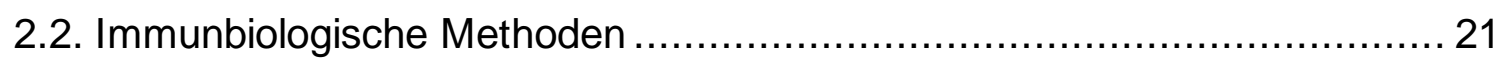

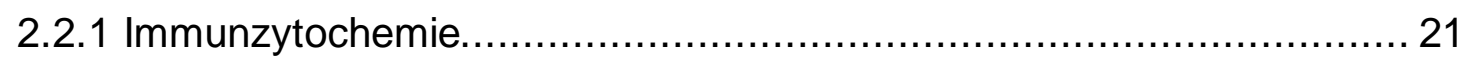

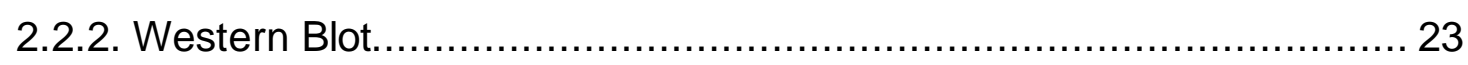

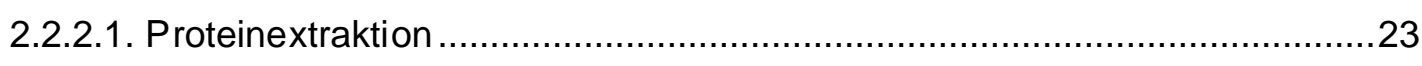

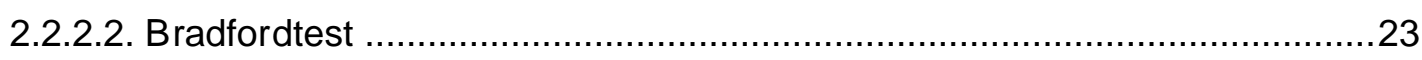

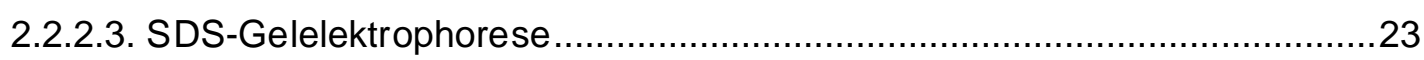

2.2.2.4. Übertragen der aufgetrennten Proteine auf PVDF-Membran .....................24

2.2.2.5. Immunchemischer Nachweis der Proteinbanden .....................................25

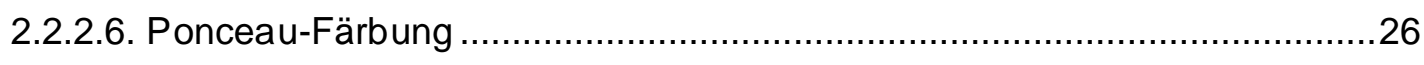

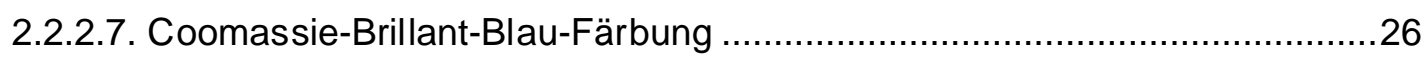

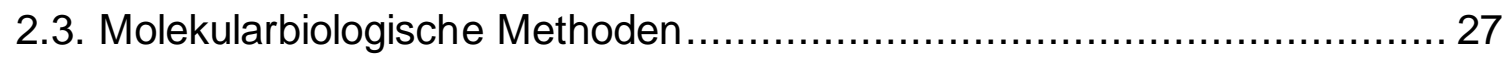

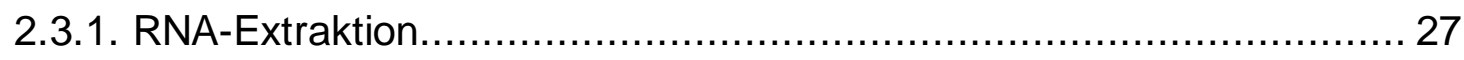

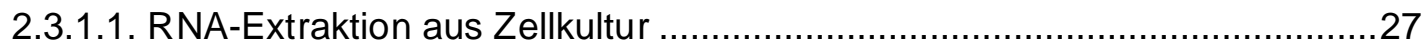

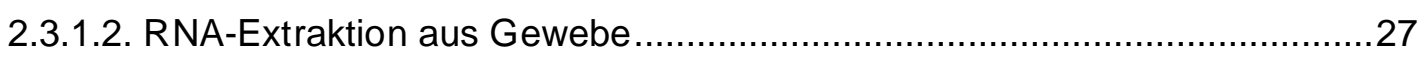

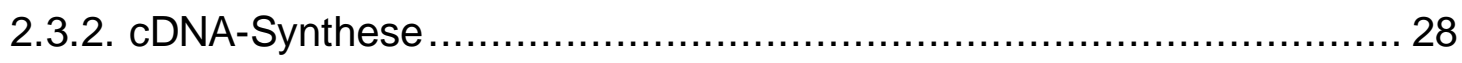

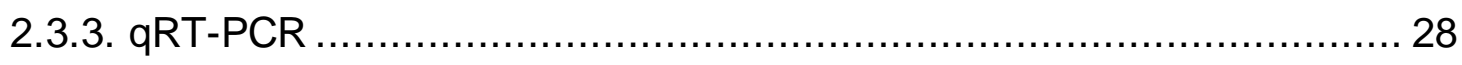

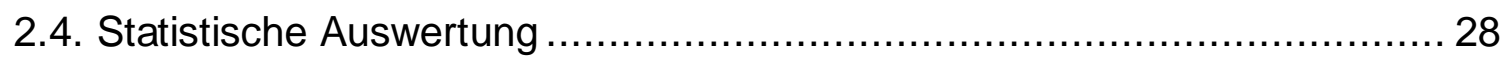

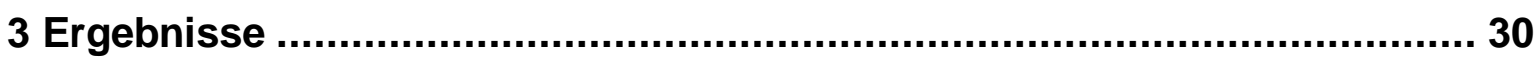

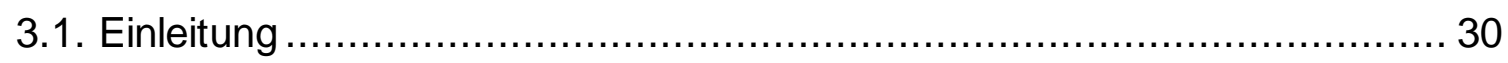

3.2. Proteinexpression von NLRP3 in Muskelzellen nach inflammatorischem

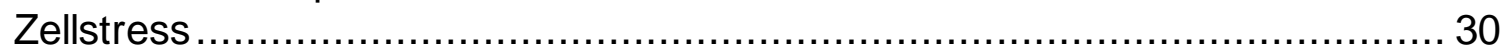

3.2.1 Proteinnachweis mittels Immunzytochemie................................... 30

3.2.2. Proteinnachweis mittels Western Blot.......................................... 32

3.3. mRNA-Expression in gesunden Muskelzellen nach inflammatorischen

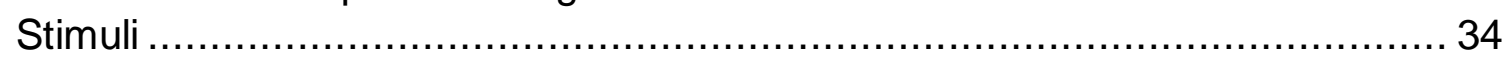

3.4. mRNA-Expression in Muskelproben von Myositispatienten ..................... 35

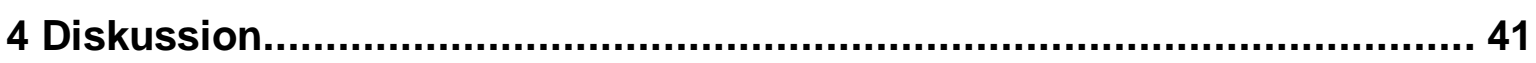

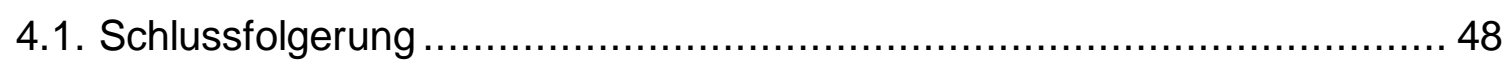

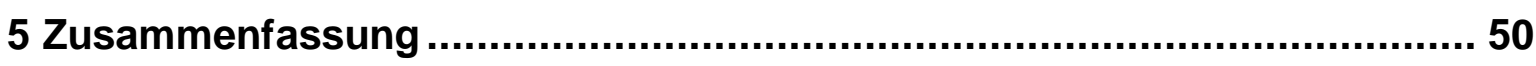

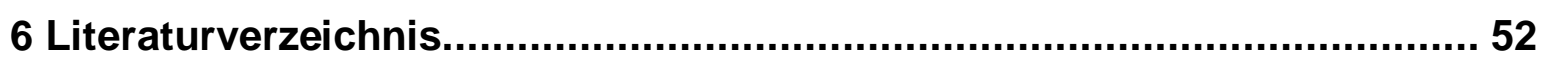




\section{Abkürzungsverzeichnis}

APC

Antigen presenting cells

APP

Amyloid Precursor Protein

ASC Apoptosis-Associated Speck like Protein Containing A Caspase Recruitment Domain

CCL

CDNA

CC-motif Liganden

CK

complementary DNA

CXCL

Creatinkinase

DAMPS

CXC-motif Liganden

DM

Damage-Associated-Molecular-Patterns

DNA

Dermatomyositis

ER

Desoxyribonukleinsäure

GAPDH

GBP

IBM

ICC

ICOS

ICOS-L

IFN

IIM

IL

IVIG

LGMD

LPS

$\mathrm{MHC}$

mRNA

Endoplasmatisches Retikulum

Glycerinaldehyd-3-phosphat-Dehydrogenase

Guanylate-Binding-Proteine inclusion body myositis Immunzytochemie

inducible T-cell Costimulator

inducible T-cell Costimulator-Liganden

Interferon

inflammatorisch idiopathische Myositiden Interleukin

intravenöses Immunglobulin

limb-girdle muscular dystrophy

Lipopolysaccharide

NK-Zellen

Major Histocompatibility Complex messenger RNA

NLR

NLRC5

NLRP3

NM

PAMPS

PBS

PFA

PM

PROMM

Natürliche Killer-Zellen

NOD-Like-Receptors

NOD-like receptor family CARD domain containing 5

NOD-like Receptor Protein 3

Nekrotisierende Myopathie

Pathogen-Associated-Molecular-Patterns

Phosphate Buffered Saline

Perfluoralkoxy-Polymere

PRR

Polymyositis, Polymyositis

RNA

Myotone Dystrophie Typ II

RT-PCR

Pattern Recognition Receptors

Ribonukleinsäure

TLR

Reverse-Transkriptase-Polymerase-Kettenreaktion

TNF

Toll like Rezeptoren

ZNS

Tumor Nekrose Faktor

Zentrales Nervensystem 


\section{Einleitung}

\subsection{Einschlusskörpermyositis (IBM)}

Die Einschlusskörpermyositis (im Folgenden inclusion body myositis, abgekürzt IBM, genannt) wird nach den Leitlinien der Deutschen Gesellschaft für Neurologie der Klasse der inflammatorisch idiopathischen Myositiden (IIM) zugeordnet (DGN 2015). Neben der IBM finden sich dort auch die Polymyositis (PM), die Dermatomyositis (DM) und die nekrotisierende Myopathie (NM). Die Prävalenz all dieser Erkrankungen in der deutschen Bevölkerung liegt bei 1:100.000. Dabei ist die DM die insgesamt häufigste Form, die IBM ist jedoch in der Bevölkerungsgruppe über 50 Jahre die häufigste Entität (Breithaupt und Schmidt 2014). Vor allem Männer im Alter über 50 Jahre sind von der IBM betroffen. In der Literatur werden schwankende Angaben zur Inzidenz der Erkrankung gemacht. Für die Gesamtpopulation wird ein Auftreten der IBM von 4,9-14,9 Fällen auf 1 Million angegeben, die jedoch bei Betrachtung der Altersgruppe über 50 Jahre auf 35,3/1.000.000 ansteigt (Breithaupt und Schmidt 2014).

\subsubsection{Symptomatik und Verlauf}

Charakterisiert ist die IBM durch einen progressiven Verlauf mit zunehmender asymmetrischer Muskelschwäche der distalen und proximalen Skelettmuskulatur. Der Musculus quadriceps femoris und die tiefen Fingerflexoren sind typischerweise die am stärksten beteiligten Muskelgruppen. Zusätzlich kann die Pharynxmuskulatur betroffen sein, was sich in einer unterschiedlich stark ausgeprägten Dysphagie äußert und von Patienten häufig erst nach gezielter Nachfrage geschildert wird (Schmidt und Dalakas 2013).

Langfristig ist mit dem Verlust der Gehfähigkeit und Komplikationen der auftretenden Dysphagie zu rechnen (Breithaupt und Schmidt 2014).

\subsubsection{Diagnostik}

In der Vergangenheit wurden die Kriterien zur Diagnosestellung einer IBM wiederholt überarbeitet. Aktuell werden klinische Symptomatik, laborchemische Auffälligkeiten sowie pathologische Kriterien betrachtet, um die Erkrankung zu diagnostizieren. Dabei wird in eine klinisch-pathologisch gesicherte IBM, eine klinisch gesicherte IBM oder eine mögliche IBM unterteilt (Rose et al. 2013). 
Laborchemisch lässt sich oftmals eine moderate Creatinkinase (CK)-Erhöhung nachweisen. Diagnostisch relevant ist eine Muskelbiopsie, welche die histopathologischen Merkmale der IBM aufweist. Dazu zählen einerseits lymphozytäre Infiltrate und andererseits degenerative Veränderungen wie Vakuolenbildung, Fasergrößenvariationen, Zentralisierung von Zellkernen und Proteinaggregationen.

Neben der Biopsie wird ein Erkrankungsalter über 45 Jahre, eine Erkrankungsdauer von mehr als zwölf Monaten und das klinische Bild des Patienten sowie das Verteilungsmuster der aufgetretenen Muskelparesen in die Diagnosestellung einbezogen (Rose et al. 2013; Schmidt 2018).

\subsubsection{Pathogenese}

Die Pathogenese der IBM ist bis zum heutigen Zeitpunkt nicht eindeutig aufgeklärt. Es zeigt sich histologisch jedoch eine Kombination aus entzündlichen und degenerativen Prozessen.

Muskelfasern von IBM-Patienten weisen eine Hochregulation des antigenpräsentierenden Major Histocompatibility Complex I (MHC-I) und eine zusätzliche Expression des inducible T-cell Costimulator Ligand (ICOS-Liganden) auf. Durch diese Liganden ist eine Kostimulation von $\mathrm{CD}^{+}$zytotoxischen T-Zellen möglich. Diese Aktivierung autoimmunwirksamer TZellen bewirkt eine Ausschüttung des zytolytischen Proteins Perforin und eine Invasion der T-Zellen in MHC-I- und ICOS-L-exprimierende Muskelzellen sowie eine Zellnekrose (Schmidt et al. 2004; de Paepe und Zschüntzsch 2015).

Somit scheinen die Muskelfasern selbst die Funktion von professionellen Antigen-präsentierenden Zellen (APCs) übernehmen zu können und bewirken eine klonale Expansion der $\mathrm{CD}^{+}$T-Zellen in ihrer Umgebung (Schmidt et al. 2004; Ding et al. 2018).

Zusätzlich konnte in einigen Versuchen demonstriert werden, dass Muskelfasern mit der Ausschüttung von proinflammatorischen Zytokinen (IFN- - , TNF- $\alpha$, IL-1 $1 \beta$ und IL-6) ein proentzündliches Milieu schaffen. Das führt zur weiteren Migration von T-Zellen und Aufrechterhaltung der Inflammation (Figarella-Branger et al. 2003). Die Entzündungsaktivität scheint zugleich mit dem Ausmaß der degenerativen Veränderungen zu korrelieren, wobei im Speziellen ein hohes Maß an Interleukin 1- $\beta$ (IL-1ß) mit der Akkumulation des Amyloid Precursor Proteins (APP) einhergeht (Keller et al. 2017). 
Die Rolle der B-Zell Aktivierung in der Pathogenese der IBM verbleibt weiterhin unklar. Im Serum von circa $60 \%$ der Patienten konnten Antikörper gegen ein 43 kDa großes Protein nachgewiesen werden. Als Antikörper gegen ein muskuläres Protein mit dem relativen molekularen Gewicht von 44.000 wurde dieser als MUP44-Antikörper bezeichnet. Spätere Studien definierten dieses muskuläre Protein als die cytosolische $5^{\prime}$-Nukleotidase $1 \mathrm{~A}$ (cN1A). Diese Antikörper konnten jedoch auch bei Patienten anderer Myositiden isoliert werden und scheinen somit nicht spezifisch für die IBM zu sein (Salajegheh et al. 2011; Pluk et al. 2013).

Histopathologische Erscheinungen der Degeneration sind in Form von Proteinaggregaten als Einschlusskörper darstellbar. Bestandteile der Aggregate sind vorwiegend $\beta$-Amyloid (Schmidt et al. 2008), phosphoryliertes Tau-Protein, Presenilin, p62 und a-Synuclein. Diese Proteinablagerungen sind vor allem bei Patienten mit neurodegenerativen Erkrankungen, wie z.B. der Alzheimer Demenz, Morbus Parkinson und M. Huntington im Gehirn nachweisbar (Schmidt und Dalakas 2013). Auch weisen Patientenbiopsien eine große Anzahl an ragged-red-fibers auf, die in dem Ausmaß in der DM und PM nicht vorhanden sind. Des Weiteren scheinen Autophagiesysteme bei IBM-Erkrankten in ihrer Funktion beeinträchtigt, wodurch es zu weiterer Akkumulation von degenerativen Proteinen in den Fasern kommt (Benveniste et al. 2015).

\subsubsection{Therapie}

Die IBM verläuft in der Regel chronisch progredient. Therapieerfolge durch Glucokortikosteroide, Immunsuppressiva wie Methotrexat und monoklonale Antikörper wie Alemtuzumab sind oft nicht oder nur von kurzer Dauer zu verzeichnen. Die Leitlinie für Myositissyndrome sieht einen Therapieversuch mit intravenösen Immunglobulin (IVIG)-Infusionen in vier- bis sechswöchigem Abstand vor. Dabei sollte eine Stabilisierung des Krankheitsverlaufs erreicht werden. Der Krankheitsprogress wird über regelmäßige Muskelkraftmessungen und symptomorientierte Patientenfragebögen überprüft. Im Fall der Einschlusskörpermyositis liegt derzeit, aufgrund mangelnder Datenlage und fehlender randomisierter Langzeitstudien, eine Therapieleitlinie der Entwicklungsstufe S2 vor (DGN 2015).

\subsection{Myositiden und Myopathien im Vergleich}

In dieser Arbeit wurden Muskelbiopsien der DM, PM, NM sowie von Muskeldystrophien vergleichend betrachtet und auf Regulation eines Inflammasomproteins molekularbiologisch untersucht. Aus diesem Grund werden im Folgenden die Grundzüge der klinischen Erscheinung und der Pathogenese im Einzelnen besprochen. 
Als Schlüsselsymptom aller idiopathisch inflammatorischen Myositiden wird eine Muskelschwäche mit gleichzeitig nicht beeinflussten Muskeleigenreflexen und Sensibilität beschrieben.

Sowohl bei der PM, der NM als auch der DM kann die pharyngeale und cervikale Muskulatur mitbetroffen sein. Es zeigt sich häufig eine Beteiligung der Atemmuskulatur und des Herzens, woraus Kardiomyopathien und EKG-Veränderungen resultieren können. Ein zusätzlicher Befall der Lunge kann bei einem Anti-Synthetase-Syndrom oder einer OverlapMyositis auftreten.

Des Weiteren wurden für alle Entitäten Assoziationen zu Haplotypen der HLA-Komplexe zugeordnet. Spezifische und unspezifische Antikörperreaktionen, welche sich bei einem Großteil der Patienten zeigten, werden nach aktuellem Stand für die Klassifikation verschiedener Krankheitssubtypen verwendet (DGN 2015). Da diese Antikörper nicht bei allen Patienten gefunden werden und in dieser Arbeit nicht weiter untersucht wurden, werden sie jedoch zugunsten der Übersichtlichkeit in dieser Dissertation nicht weiter aufgeführt.

\subsubsection{Dermatomyositis (DM)}

Die DM tritt mit einer zweigipfligen Altersverteilung als juvenile oder adulte Erkrankung mit einer Prädominanz des weiblichen Geschlechts auf. Je nach Altersklasse schwanken Inzidenzangaben und werden kumulativ in einem Bereich von 2-9/1.000.000. Patienten angegeben (DGN 2015).

Das Auftreten von charakteristischen Hautveränderungen, die einer muskulären Symptomatik vorausgehen können oder sogar gänzlich ohne Muskelschwäche auftreten (amyopathische Dermatomyositis), ist bei jeder Diagnosestellung einer Myositis zu beachten. Eine wichtige Differentialdiagnose der Dermatomyositis ist vor allem bei amyopathischem Auftreten der systemische Lupus erythematodes.

Klinisch dominant sind periorbitale Ödeme sowie ein symmetrisches rosa-violettes Erythem an Wangen, Nacken und Dekolleté mit verstärkter Photosensitivität der gesamten Haut. Zeitgleich können ubiquitär Pigmentierungsstörungen, Teleangiektasien, erweiterte Kapillaren, epidermale Atrophien und Gottron Papeln an den Fingergelenken auftreten. Diese Symptomatik weitet sich teilweise bis zu kutanen Ulzerationen, einem ausgeprägten Raynaud-Phänomen und exfoliativer Erythrodermie aus.

Bei Dermatomyositispatienten besteht ein vierfach erhöhtes Malignomrisiko im Vergleich zur Normalpopulation (Hill et al. 2001). Die Diagnose der DM kann der Erstdiagnose eines 
Malignoms bereits fünf Jahre vorausgehen, weshalb eine hochfrequente klinische Kontrolle und Tumorsuche bei diesen Patienten nach Myositisdiagnosestellung indiziert ist.

Pathogenetisch ist auch die DM nicht vollends aufgeklärt. Im Vergleich zur IBM und der PM scheint diese jedoch Antikörper-vermittelt zu entstehen. Eine primär humorale Immunantwort mit perivaskulären Lymphozyteninfiltraten, perifaszikulärer Atrophie und Komplementablagerungen dominiert in der histopathologischen Untersuchung (Figarella-Branger et al. 2003; Wiendl et al.). Bereits nach kurzem Krankheitsverlauf können vaskuläre Veränderungen und Endothelschädigung mit inflammatorischem Infiltrat aus CD4 ${ }^{+}$Zellen, B-Lymphozyten und Makrophagen im histologischen Präparat beobachtet werden. Die MHC-I Expression ist bei dieser Erkrankung vorwiegend perifaszikulär erhöht (Figarella-Branger et al. 2003).

\subsubsection{Polymyositis (PM)}

Die Polymyositis tritt ebenfalls mit einer weiblichen Prädominanz im Verhältnis von 2:1 auf. Wie bereits beschrieben ist ein symmetrisch auftretender, proximaler Muskelbefall typisch. Generell wird die Eigenständigkeit der Diagnose der Polymyositis von einigen Autoren in Frage gestellt. Aufgrund pathologischer Ähnlichkeiten liegt häufig eine unklare Abgrenzung zur IBM vor. Im Krankheitsverlauf werden immer wieder Übergänge in eine IBM beschrieben (de Paepe et al. 2008). Zusätzlich lassen ein gehäuftes Auftreten mit anderen Immunerkrankungen und ein nachträglicher Nachweis einer genetisch gesicherten hereditären Myopathie die Zuordnung zu einer PM in wiederholten Fällen anzweifeln (Schoser 2009).

Patienten mit einer Polymyositis zeigen ein zweifach erhöhtes Malignomrisiko, wobei das Auftreten der Myositissymptomatik zur Demaskierung des Malignoms führen kann und zur Tumorerstdiagnose führt (Hill et al. 2001).

Die Pathogenese der Polymyositis scheint vorwiegend T-Zell-vermittelt. Histologisch zeigen sich disseminiert nekrotische Muskelfasern und ein ubiquitär exprimiertes MHC-I.

\subsubsection{Nekrotisierende Myopathie (NM)}

Die Nekrotisierende Myopathie zeichnet sich durch einen akuten bis subakuten Beginn mit deutlicher, symmetrisch vorhandener proximaler Muskelschwäche und hohen Serum-CKWerten aus. Als Einzige der IIMs besteht ein nahezu ausgeglichenes Verhältnis von weiblichen zu männlichen Patienten. Neben dem idiopathischen Auftreten werden Fälle der NM paraneoplastisch beobachtet. Auch toxische Medikamentenwirkungen können zu einer Myopathie führen. Eine seltene Nebenwirkung von z.B. Statinen ist eine Rhabdomyolyse 
oder Triggerung einer Nekrotisierenden Myopathie (Kassardjian et al. 2015). Histologisch imponieren nekrotische Muskelfaserareale mit gering bis mäßig erhöhter Expression von MHC-I mit Betonung in den nekrotischen Faserarealen. Inflammatorische Zellinvasion ist kaum zu beobachten, einzig eine sekundäre Invasion von Makrophagen stellt sich histologisch dar. Komplementaktivierung und -bindung am Kapillarendothel und an Muskelfaseroberflächen ist teilweise zu beobachten (Schmidt 2018). 
Tabelle 1) Übersicht der Idiopathisch inflammatorischen Myositiden modifiziert aus „Myositissyndrome“" Leitlinien für Diagnostik und Therapie in der Neurologie (DGN 2015).

\begin{tabular}{|c|c|c|c|c|}
\hline Merkmale & IBM & DM & PM & NM \\
\hline $\begin{array}{l}\text { Männer: } \\
\text { Frauen }\end{array}$ & $3: 1$ & $1: 2$ & $1: 2$ & $1: 1$ \\
\hline Altersgipfel & $>45$ Jahre & 5-15 und 45-65 Jahre & $>18$ Jahre & $>18$ Jahre \\
\hline $\begin{array}{l}\text { Auftreten, } \\
\text { Verlauf }\end{array}$ & $\begin{array}{l}\text { langsam progredient, } \\
\text { chronisch >12 Monate }\end{array}$ & $\begin{array}{l}\text { akut-subakut, von kurzen } \\
\text { Verläufen bis chronisch }\end{array}$ & $\begin{array}{l}\text { akut-subakut, in der } \\
\text { Regel chronisch }\end{array}$ & $\begin{array}{l}\text { akut-subakut, } \\
\text { chronische Verläufe } \\
\text { möglich }\end{array}$ \\
\hline Paresen & $\begin{array}{l}\text { proximal und distal, } \\
\text { asymmetrisch, } \\
\text { Prädilektionsstellen: } \\
\text { Kniestrecker > } \\
\text { Hüftbeuger und } \\
\text { Fingerbeuger> } \\
\text { Schulterabduktoren }\end{array}$ & $\begin{array}{l}\text { Proximal > distal, } \\
\text { symmetrisch }\end{array}$ & $\begin{array}{l}\text { Proximal > distal, } \\
\text { symmetrisch }\end{array}$ & $\begin{array}{l}\text { Proximal > distal, } \\
\text { symmetrisch }\end{array}$ \\
\hline $\begin{array}{l}\text { Muskel- } \\
\text { atrophie }\end{array}$ & deutlich & gering & mäßig & mäßig \\
\hline $\begin{array}{l}\text { Muskel- } \\
\text { biopsie }\end{array}$ & $\begin{array}{l}\text { endomysiales } \\
\text { Rundzellinfiltrat, } \\
\text { Invasion von intakten } \\
\text { Muskelzellen, } \\
\text { Myodegenerativ mit } \\
\text { Faseratrophie, } \\
\text { rimmed vacuoles, } \\
\text { eosinophile } \\
\text { Einschlüsse }\end{array}$ & $\begin{array}{l}\text { perimysiale und } \\
\text { perivaskuläre } \\
\text { Rundzellinfiltrate, } \\
\text { vorwiegend Lymphozyten, } \\
\text { Komplementablagerung um } \\
\text { Kapillare, perifaszikuläre } \\
\text { Atrophie und Nekrose }\end{array}$ & $\begin{array}{l}\text { endomysiales } \\
\text { Rundzellinfiltrat aus } \\
\text { Lymphozyten mit } \\
\text { Invasion von intakten } \\
\text { Muskelzellen, } \\
\text { Einzelfasernekrosen }\end{array}$ & $\begin{array}{l}\text { sekundäre } \\
\text { Makrophageninfiltration } \\
\text {, kaum T-Zellinfiltrat, } \\
\text { ausgedehnte Nekrosen }\end{array}$ \\
\hline $\begin{array}{l}\text { Immun- } \\
\text { histologie }\end{array}$ & \begin{tabular}{|l|} 
CD8>CD4-Zellen, \\
Makrophagen, \\
Invasion von $\mathrm{CD}^{+}-\mathrm{T}-$ \\
Zellen in $\mathrm{MHCl}-$ \\
Exprimierende Zellen, \\
$\beta$-Amyloid und \\
weitere degenerative \\
Proteinablagerungen \\
\end{tabular} & $\begin{array}{l}\text { CD20+-B-Zellen, } \\
\text { Makrophagen, CD4+-T- } \\
\text { Zellen, } \\
\text { Komplementablagerung }\end{array}$ & $\begin{array}{l}\text { CD8 > CD4-Zellen, } \\
\text { Makrophagen, } \\
\text { Invasion von } \mathrm{CD}^{+}-\mathrm{T}- \\
\text { Zellen in } \mathrm{MHCl}- \\
\text { Exprimierende Zellen }\end{array}$ & Makrophagen \\
\hline $\begin{array}{l}\text { MHC-I- } \\
\text { Expression }\end{array}$ & ubiquitär & perifaszikulär & ubiquitär & $\begin{array}{l}\text { gering erhöht an } \\
\text { nekrotischen } \\
\text { Faserarealen }\end{array}$ \\
\hline $\begin{array}{l}\text { Elektronen- } \\
\text { mikros- } \\
\text { kopisch }\end{array}$ & \begin{tabular}{|l|} 
Tubulofilamente bis \\
$18 \mathrm{~nm}$, sarkolemmale \\
und nukleäre Fibrillen, \\
autophagische \\
Vakuolen \\
\end{tabular} & $\begin{array}{l}\text { tubulovesikuläre } \\
\text { Einschlüsse im } \\
\text { Gefäßendothel }\end{array}$ & $\begin{array}{l}\text { keine spezifischen } \\
\text { Auffälligkeiten }\end{array}$ & $\begin{array}{l}\text { keine spezifischen } \\
\text { Auffälligkeiten }\end{array}$ \\
\hline $\begin{array}{l}\text { Immun- } \\
\text { therapie- } \\
\text { ansprechen }\end{array}$ & nicht oder minimal & ja & ja & häufig ja \\
\hline
\end{tabular}




\subsubsection{Muskeldystrophien}

Die Gruppe der progressiven Muskeldystrophien unterscheiden sich in grundlegender Ursache, Symptomatik und histologischem Erscheinungsbild. Durch eine Mutation von jeweiligen Genen von Muskelproteinen kommt es im Verlauf der Erkrankung zu einer Atrophie und Paresen der Skelettmuskulatur. Die Mutationen können sowohl autosomalrezessiv, als auch autosomal-dominant vererbt werden und bedingen jeweils ein erkrankungsspezifisches Verteilungsmuster der Atrophien und Paresen. In bestimmten Muskeldystrophien ist die kardiale Muskulatur ebenfalls betroffen und führt $\mathrm{zu}$ Kardiomyopathien oder Herzrhythmusstörungen.

Viele Dystrophieformen weisen laborchemisch eine Erhöhung der CK und neurophysiologisch ein myopathisches Muster auf. Histologisch zeigen Muskelbiopsien der Patienten vor allem Kaliberschwankungen, zentralisierte Nuclei sowie einen Umbau in Fett- und Bindegewebe (Meola und Cardani 2015).

In dieser Arbeit verwendete Proben umfassten vorwiegend Patienten mit der Diagnose einer Muskeldystrophie Typ Becker, der Muskeldystrophie vom Gliedergürteltyp (LGMD) und der Myotonen Dystrophie Typ II (PROMM). Für die PROMM wird in der Literatur ein Hauptmanifestationsalter bis zum 50. Lebensjahr angegeben. Es handelt sich bei der Krankheitsform um einen autosomal dominanten Erbgang einer CCTG-Nukleotid-Repeat-Erkrankung (DGN 2016). Bei der Muskeldystrophie Typ Becker handelt es sich um einen X-Chromosomal rezessiven Erbgang mit einer Dystrophinmutation. Durch den Erbgang bedingt sind ausschließlich Jungen klinisch betroffen. Die Erstmanifestation der Erkrankung findet sich vorwiegend im späten Jugendalter bis zum 20. Lebensjahr, wobei auch deutlich ältere Erstmanifestationen auftreten. Der Gliedergürtelmuskeldystrophie liegen verschiedene Mutationen zugrunde. Eine der häufigsten Mutationen ist dabei eine autosomal dominant, oder rezessiv vererbte Verminderung von Calpain 3 und manifestiert sich bis zum mittleren Lebensalter.

\subsection{Inflammasom}

\subsubsection{Pattern Recognition Receptors (PRRs)}

Pattern Recognition Receptors sind Teil der angeborenen Immunantwort des Körpers. Es handelt sich um Proteine, die pathogene Strukturen auf der Zelloberfläche oder im Zytosol binden und eine Immunantwort hervorrufen.

Eine Signalkaskade wird als Antwort auf mikrobiellen oder endogenen Zellstress und Zellschaden gestartet. Eine Unterteilung von PRRs in Untergruppen wird anhand der Definition 
der verschiedenen Rezeptoranteile vorgenommen. So existieren Familien mit Toll-like-Rezeptoren (TLRs), C-type Lectin Rezeptoren (CLRs), RIG-I-like Rezeptoren (RLRs) und Nucleotide-Binding and Oligomerization Domain (NOD)-like Rezeptoren (Lamkanfi und Kanneganti 2010).

Als Aktivatoren der PRRs dienen Pathogen-Associated-Molecular Patterns (PAMPS) und Damage-Associated Molecular Patterns (DAMPS).

Zu den PAMPS zählen vor allem beschädigte DNA und RNA, Proteoglykane von mikrobiellen Zellwänden und Virusbestandteile. Als DAMPs werden unter anderem extrazelluläres Adenosin-Triphosphat, Wirts-DNA und Harnsäurekristalle gezählt. DAMPs werden sowohl bei Zellzerstörung durch Traumata, als auch bei metabolischen Störungen und Infektionen freigesetzt (Menu und Vince 2011).

\subsubsection{NOD-Like Receptors (NLR)}

Die NOD-Like-Receptor-Familie (NLR), die derzeit 23 definierte humane Gene umfasst, wird in drei Subtypen unterteilt. Dazu zählen die Nukleotide-Binding Oligomerization Domain Containing Proteins (NOD-Proteine), die NOD-LRR and Pyrin-Domain Containing Proteins (NLRP-Proteine) und eine Ice Protease-Activating-Factor-(IPAF)-Familie (Ozaki et al. 2015).

Allen NLRs ist ein gemeinsamer Grundaufbau zuzuschreiben. Dieser besteht aus einer Cterminalen Leucine-Rich-Repeat-Region (LRRs), einer anschließenden Nucleotide Binding and Oligomerization Domain (NACHT oder NOD) und einer Effektordomäne am N-Terminus des Proteins. Die LRR-Region unterstützt den Ruhestatus des Komplexes und vollführt nach einem Stimulus eine Konformationsänderung. Die zentrale NACHT-Region oligomerisiert während der Aktivierung zu Proteinkomplexen. Die Effektordomäne besteht entweder aus einer Caspase Activation and Recruitment Domain (CARD), Baculorviral Inhibitor of Apoptosis Protein Repeat (BIR) oder einer Pyrin-Domäne. Je nach angeschlossenem NTerminus wird der weitergehende Effekt des aktivierten NLR-Komplexes bestimmt (Menu und Vince 2011).

Als Inflammasom werden derzeit fünf Proteinkomplexe definiert. Drei dieser Proteine gehören zu der NLRP-Familie (1-3), ein Absent-in-Melanoma-Protein (AIM) und ein IPAF-Protein (NLRC4) komplettieren die Inflammasomgruppe. Für jedes Inflammasom konnte ein spezifischer Stimulus identifiziert werden (Ozaki et al. 2015). 


\subsubsection{NOD-Like Receptor Protein 3 (NLRP3)}

\subsubsection{Aufbau}

NLRP3 (auch Cryopyrin genannt) ist ein cytosolisches Protein aus 1016 Aminosäuren und wird von dem cias1 Gen auf dem humanen Chromosom 1 codiert (Lamkanfi und Kanneganti 2010).

Aufgebaut ist das NLRP3 Protein aus einer zentralen NOD-Region, zwölf LRR-Motiven am c-Terminus und einer Pyrindomäne am N-Terminus.

Durch die Pyrindomäne interagiert das NLRP3 mit einem Apoptosis-Associated Speck Like Protein Containing A Caspase Recruitment Domain (ASC-Protein). Dieses besteht aus einer bindenden Pyrinregion und einer caspaseaktivierenden Domäne (CARD). Über eine Interaktion der CARD Regionen von ASC und Pro-Caspase 1 erfolgen einer Dimerisierung der Caspase und eine Aktivierung des Enzyms.

\subsubsection{Aktivierung und klinische Bedeutung}

Das NLRP3-Inflammasom wird durch vielfältige Stimuli aktiviert. Sowohl Bakterien als auch Viren, Pilze und DAMPs aktivieren das NLRP3-Inflammasom. Der genaue Ablauf und die beteiligten Akteure der Aktivierung bleiben bis zum aktuellen Zeitpunkt unklar. Es werden mehrere Modelle diskutiert, die jeweils zwei Schritte umfassen.

Schritt eins, das sogenannte „Priming“, erfolgt über eine DAMP-/PAMP- Erkennung von tolllike-Rezeptoren an der Zellmembranoberfläche. Diese führt zu einer NFkB-Induktion und einer Produktion von NLRP3 und pro-IL-1 $\beta$. Der zweite Schritt umfasst die eigentliche Aktivierung und Oligomerisierung der NLRP3-Proteine zu einem aktiven Komplex. Drei Varianten der Aktivierung werden in der Literatur diskutiert. Zum einen soll ein $\mathrm{K}^{+}$-Ausstrom aus der Zelle als genereller Aktivator mehrerer Inflammasome gelten. Als zweiter möglicher Aktivierungspfad werden reaktive Sauerstoff-Spezies (ROS) aus verletzten Mitochondrien gesehen, da direkte Inhibition und Autophagie von ROS eine Unterdrückung des NLRP3 zeigten. Als drittes Modell gilt aus lysosomalen Prozessen freigesetztes Cathepsin B, welches die Aktivierung des Inflammasoms bedingt (Davis et al. 2011; Robbins et al. 2014).

Der aktivierte Komplex führt über das ASC und eine Aktivierung von pro-Caspase 1 zur Freisetzung von proinflammatorischem IL-1 $\beta$ (Ozaki et al. 2015).

Klinisch wurde das NLRP3-Inflammasom bei der Entdeckung der Cryopyrin-AssociatedPeriodic-Syndromes (CAPS) auffällig. Dabei handelt es sich um drei aseptische Entzündungskrankheiten, die wiederkehrende Fieberschübe, Urtikaria, Fatigue, 
Bindehautentzündungen und Gelenkschmerzen beinhalten. Durch einen gain-of-functionGendefekt des NLRP3 kommt es schubartig zu hohen IL-1 $\beta$-Ausschüttungen und zur Autoinflammation. Unter dem Begriff CAPS sind die drei Erkrankungen Familial Cold Autoinflammatory Disease (FCAS), das Muckle-Wells Syndrome (MWS) und die Neonatal Onset Multi-systemic Inflammatory disease/ Chronic Infantile Neurological Cutaneous Articular Syndrome (NOMID/CINCA) zusammengefasst. Neben diesen Syndromen wird eine Überfunktion des Inflammasom auch bei dem familiären mediterranen Fieber vermutet (Menu und Vince 2011).

Eine deutliche konstitutive Expression des NLRP3 ließ sich in Mononukleären Zellen des Blutes, Granulozyten, Neutrophilen, Dendritischen Zellen, T-, B-Lymphozyten und Epithel des Oropharyngealtraktes und der Ektocervix darstellen (Kummer et al. 2007).

Da das Inflammasom auch metabolische Produkte als Aktivatoren aufweist, ist die Verbindung zu verbreiteten Erkrankungen unserer Gesellschaft zu ziehen. So sind Harnsäure, $\beta$-Amyloid-Plaques (Halle et al. 2008), Drusen-Ablagerungen, freie Fettsäuren, LDL und Cholesterol sowohl Aktivatoren von NLRP3 als auch grundlegende Ursachen in der Entstehung von Gicht, Alzheimer, der Altersbedingten Makuladegeneration, Typ II Diabetes und Atherosklerose (Menu und Vince 2011; Robbins et al. 2014).

Neben der Hochregulation bei systemischen Erkrankungen konnte auch eine Hochregulation des Inflammasoms in einigen Geweben wie der Niere und der Leber gezeigt werden. In Nierenbiopsien zeigte sich sowohl bei akuten Nierenschädigungen wie der akuten Tubulusnekrose und rapid progressiven Glomerulonephritiden als auch bei chronischen Nierenerkrankungen eine deutlich erhöhte Expression des NLRP3 im Vergleich zu gesunden Nierenbiopsien (Vilaysane et al. 2010). Leberbiopsien von Patienten mit viralen Hepatitiden und der nichtalkoholischen Steatohepatitis wiesen sowohl direkt bei Diagnosestellung als auch im chronischen Stadium erhöhte NLRP3-Transkripte auf (Farrell et al. 2018; Molyvdas et al. 2018). Eine Expression von NLRP3 und eine Freisetzung von IL-1 $\beta$ wurde zusätzlich auch in Adipozyten aufgezeigt. Auch im Skelettmuskel konnte vor allem im Rahmen von Atherosklerose und Übergewicht eine Aktivierung von NLRP3 nachgewiesen werden (Robbins et al. 2014). In Dysferlin-defizienten humanen Muskelzellen konnte ebenfalls eine Hochregulation des Inflammasoms nachgewiesen werden (Davis et al. 2011; Benetti et al. 2013).

Relevant könnte die Rolle des NLRP3-Inflammasoms auf therapeutischer Ebene sein. Vor allem Patienten mit dem CAP-Syndrom profitieren derzeit von einer medikamentösen Blockade des IL-1 $\beta$, welches als Endprodukt der Signalkaskade entsteht. Weitere Ansätze zur 
Blockade der Signaltransduktion vor der Produktion von IL-1 $\beta$ werden noch untersucht $(\mathrm{O}$ zaki et al. 2015).

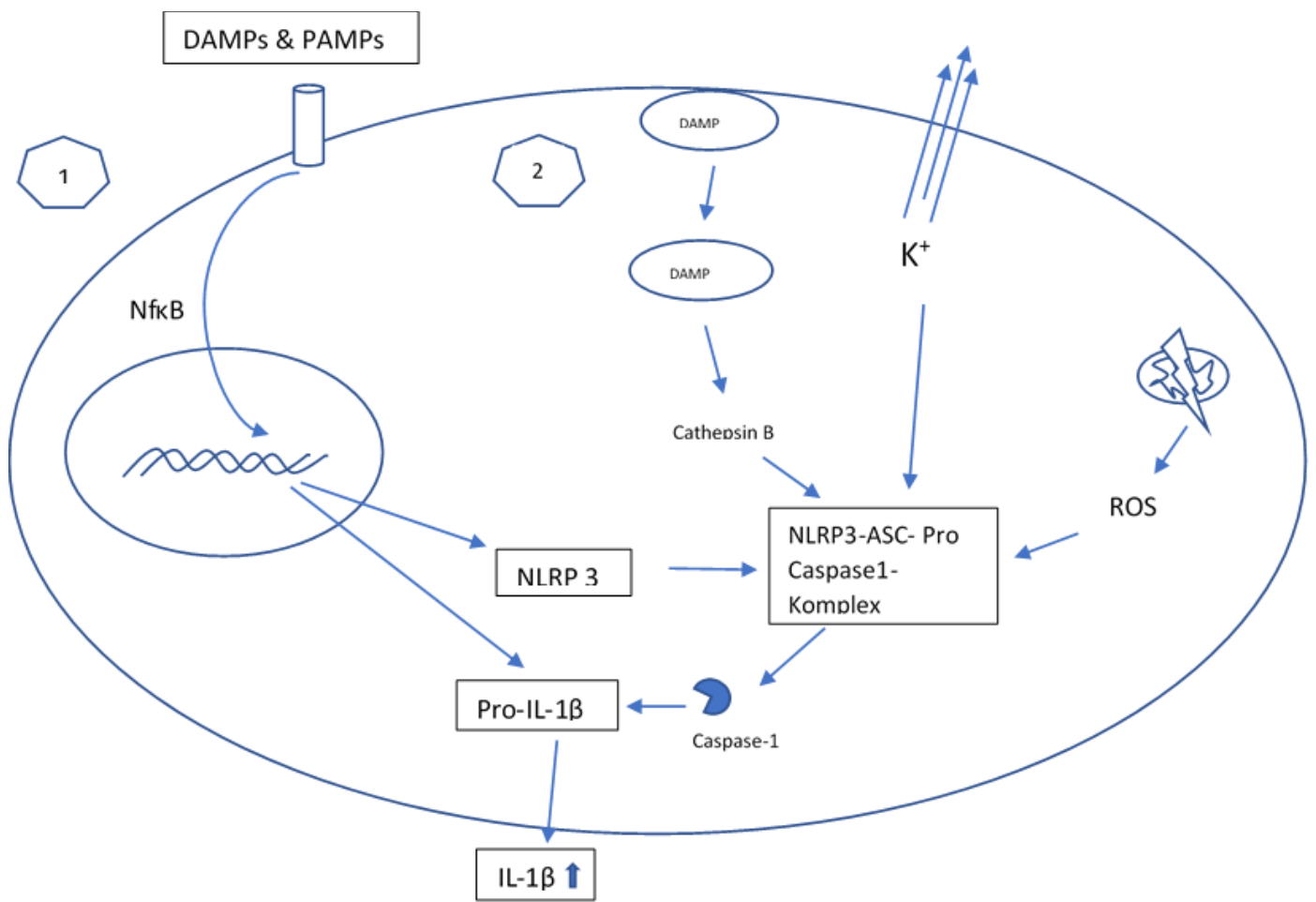

Abbildung 1: Eigene schematische Darstellung der Inflammasomaktivierung über das Priming (Schritt 1) und die Aktivierung (Schritt 2) über die drei aktuell diskutierten Aktivierungswege.

\subsubsection{NLRC5}

NLRC5 gehört wie NLRP3 zu der NOD-like Rezeptor Familie der PRRs und wird in hohem Maße in Gewebe des Immunsystems gefunden. Jedoch auch in der Lunge und dem Darmtrakt konnte ein hohes Grundmaß an NLRC5 nachgewiesen werden. Das Protein ist induziert durch IFN- $\gamma$, LPS, bakteriellen und viralen Befall der Zellen. Des Weiteren wird dem NLRC5 bei intranukleärer Lokalisation eine positiv-regulatorische Funktion auf die MHC-IExpression und somit die Aktivierung von CD8 ${ }^{+}-$T-Zellen und die Abwehr von intrazellulären, bakteriellen Infektionen zugesprochen (Yao und Qian 2013). Eine Reduktion von MHCI in NLRC5-defizienten Mäusen lässt zudem auch darauf schließen, dass NLRC5 neben dem induzierbaren Gen auch das konstitutiv exprimierte MHC-I beeinflusst (Meissner et al. 2010; Yao und Qian 2013). 


\subsection{Chemokine}

Die Gruppe der Chemokine ist eine Subgruppe der Zytokine. Die 8-14 kDa großen Signalproteine sind verantwortlich für eine zielgerichtete Bewegung von Immunzellen (Chemotaxis). Die Chemokine erwirken ihre Funktion über spezifische G-Protein gekoppelte Transmembranrezeptoren (Metzemaekers et al. 2018).

Es wird eine Unterscheidung zwischen inflammatorischen und homöostatischen Chemokinen getroffen.

Inflammatorische Zytokine werden durch Entzündung, Zellschaden oder Infektion induziert und locken Immunzellen an. Diese Chemokine binden nicht ausschließlich an spezifische Rezeptoren. Homöostatische Chemokine hingegen sind konstitutiv freigesetzte Zytokine aus dem lymphoiden Gewebe und Knochenmark. Die homöostatischen Chemokine binden streng an spezifische Rezeptoren und bewirken ein Homing von Leukozyten und die Reifung von Progenitor-B-Zellen im Knochenmark.

Allen Chemokinen gleich sind die Tertiärstruktur der Proteine und eine Ausbildung von Disulfidbrücken durch Cysteinreste am N-Terminus. Die Unterteilung der Chemokine in Untergruppen erfolgt durch eine Bestimmung von Anzahl und Position der Cysteingruppen in vier Gruppen. Dabei erfolgen eine Benennung der Struktur und ein darauffolgendes $L$ für Liganden und $\mathrm{R}$ als Rezeptorbezeichnung (Chiang und Ubogu 2013).

\subsubsection{CCL}

Die CCL-Gruppe der Chemokine besitzt zwei aufeinanderfolgende Cysteine und meistens zwei weitere Cysteine. Die CC-motif Liganden werden auch als $\beta$-Chemokine bezeichnet und gehören größtenteils zu den inflammatorischen Chemokinen. Sie fördern vorwiegend die Migration von Monozyten, Natürlichen Killer-Zellen (NK-Zellen) und dendritischen Zellen.

\subsubsection{CCL8}

CCL8 oder MCP-2 (Monocyte Chemoattractant Protein 2) bindet vorwiegend an drei Rezeptoren (CCR1, CCR2B, CCR5) und lockt neben den oben genannten Immunzellen auch Mastzellen, Eosinophile und Basophile an. Einer verstärkten CCL8 Expression wird die positive Wirkung auf die Konversion von naiven T-Zellen in CD8 ${ }^{+}$-Effektor und -Memoryzellen zugesprochen. In Studien zeigte sich hierdurch eine verbesserte immunologische Kontrolle von viralen Erkrankungen wie einer CMV-Infektion (Lisboa et al. 2015). 


\subsubsection{CCL20}

CCL20 oder LARC (Liver Activation Regulated Chemokine) wirkt stark anziehend auf Lymphozyten. Es wird vor allem in mucosa assoziiertem lymphozytärem Gewebe exprimiert und bindet an den CCR6 Rezeptor. Eine Hochregulation erfolgt durch Lipopolysaccharide (LPS) und inflammatorische Zytokine (IFN- $\beta$ und IL-1 $\beta$ ). Neben anderen wird diesem Chemokin in der Entstehung der EAE (experimentelle autoimmune Enzephalitis) zugeschrieben durch eine Hochregulation die Migration von zytotoxischen T-Zellen in das ZNS zu verstärken (Lin und Edelson 2017).

\subsubsection{CXCL}

CXC-Chemokine (a-Chemokine) besitzen zwei Cysteine, die durch eine beliebige Aminosäure voneinander getrennt werden.

\subsubsection{CXCL10}

CXCL10 wird auch Interferon-gamma Induced Protein 10 genannt. Es wird von Monozyten, Neutrophilen, Endothelzellen, Mesenchymalzellen, Hepatozyten und Fibroblasten sezerniert. CXCL10 werden in Kombination mit seinem Rezeptor CXCR3 vielfältige Auswirkungen zugesprochen. Unter anderem spielt es eine wichtige Rolle in der Chemotaxis von Makrophagen, Monozyten, T-Zellen und NK-Zellen sowie der T-Zelladhäsion und der NKZell vermittelten Zytolyse. Zudem gibt es Hinweise auf eine antiangiogenetische Wirkung (Vazirinejad et al. 2014).

Erhöhte CXCL10-Werte konnten in allen IIMs nachgewiesen werden, wobei sich bei den verschiedenen Erkrankungen eine jeweils bestimmte Ursprungsstelle und eine unterschiedliche Verteilung des Chemokins zeigte. Studien belegten eine Synthese von CXCL10 durch $\mathrm{CD}^{+}, \mathrm{CD}^{+}$und $\mathrm{CD}^{+} 8^{+}$Zellen mit variierender Ausprägung in den verschiedenen Erkrankungsgruppen. Gleichzeitig wurde eine Korrelation zwischen CXCL10-Positivität und infiltrativem Verhalten von zytotoxischen T-Zellen in der IBM aufgezeigt. Erhöhte mRNA-Werte in IBM-Biopsien sowie Proteinlevel im Blut von DMPatienten zeigten die unterschiedliche Verteilung von CXCL10 in den IIMs (de Paepe et al. 2008; de Paepe et al. 2009). 


\subsubsection{CXCL11}

CXCL11 wird durch IFN- $\beta$ und IFN- $\gamma$ induziert. Es wirkt neben CXCL9 und CXCL10 ebenfalls auf den CXCR3 Rezeptor und lockt vorwiegend aktivierte T-Zellen an. Neben der Chemotaxis scheinen die CXCR3-Liganden auch den Phänotyp und die Liniendifferenzierung der CD4+-T-Zellen zu beeinflussen. So führt eine CXCR3-Aktivierung durch CXCL11 über intrazelluläre Signalkaskaden eher zu einem Th2-Phänomtyp der Zelle oder einer regulatorische T-Zelle (Tr1-Zelle), wohingegen eine CXCR3-Aktivierung über CXCL10 zur Differenzierung der Th1 und Th17-Zelllinien bewirkt (Metzemaekers et al. 2018).

\subsubsection{Guanylate-Binding-Proteine (GBP)}

Guanylate-Binding-Proteine (GBP) sind GTPasen, welche durch IFN-y induzierbar sind. Im Generellen bewirken sie eine Immunantwort auf mikrobielle und virale Bestandteile, wobei die zellulären Wirkweisen der Proteine noch unklar sind (Wehner und Herrmann 2010). Bei den humanen GBPs wurden sieben verschiedene Proteine entdeckt, die eine Größe von 65 bis $67 \mathrm{kDa}$ besitzen. Durch Sequenzierung konnten im Mausgenom jedoch bereits zehn GBPs entschlüsselt werden, welche aufgrund der hohen Genkonservierung bereits in mehreren Wirbeltierarten bestätigt wurden und in weiteren Arten vermutet werden (Degrandi et al.2007).

\subsubsection{GBP1}

Das humane GBP1 wird vorwiegend auf virale Stimuli hin induziert und wird zu den großen GTPasen gezählt. Die GBP1-Produktion wird durch Interferone, Interleukin-1 und TNF- $\alpha$ in Endothelzellen stimuliert und wirkt antiangiogenetisch (Hammon et al. 2011). GBP1 wurde bei Patienten mit kolorektalem-Karzinom und im Liquor von Patienten mit bakterieller Meningitis nachgewiesen (Naschberger et al. 2017).

Bei Patienten, die an systemischen, inflammatorischen Autoimmunerkrankungen erkrankt sind, wie zum Beispiel der rheumatoiden Arthritis, dem systemischen Lupus erythematodes und der Systemischen Sklerose, konnte ein erhöhter Serumspiegel von GBP1 nachgewiesen werden (Hammon et al. 2011).

Da das GBP1 als bisher einzig bekanntes sezerniertes GBP anerkannt ist, wird seine Rolle als Serummarker für inflammatorische Endothelzellaktivierung diskutiert, der bei inflammatorischen Autoimmunerkrankungen zum Einsatz kommen kann (Hammon et al. 2011). 


\subsubsection{GBP5}

Das GBP5 befördert spezifisch die Akkumulation und Aktivierung des NLRP3 Inflammasoms als Antwort auf bakterielle Stimuli und gelöste, nicht kristalline Aktivatoren. So konnten Shenoy et al. zeigen, dass GBP5 über die Interaktion mit NLRP3 zu einer zellkernnahen Oligomerisation von ASC führt. Eine Defizienz von GBP5 im Mausmodell zeigte eine Fehlende Caspase-1- und IL-1 $\beta$ Aktivierung bei bekannten bakteriellen Stimulatoren des NLRP3. Des Weiteren wurde die IL-1 $\beta$-Freisetzung bei Verwendung eines kristallinen Aktivators des NLRP3 (Aluminium) oder Stimulation des AIM2 und NLRC4-Inflammasoms nicht beeinflusst (Shenoy et al. 2012).

\subsection{Zellkulturmodell für chronische Inflammation in Muskelzellen}

Um eine mögliche Regulation des Inflammasoms bei der IBM zu untersuchen, muss ein zuverlässiges Zellstressmodell gewählt werden, welches ein möglichst ähnliches Milieu schafft wie das, dem die Zellen im erkrankten menschlichen Körper ausgesetzt sind. Die Kombination aus den Zytokinen IL-1 $\beta$ und IFN- $y$ induziert unter anderem eine Überexpression von APP und eine Hochregulation von MHC-I in Myotuben, wie sie ebenfalls in Patientenbiopsien nachgewiesen werden kann (Schmidt et al. 2008).

\subsubsection{Zytokine}

\subsubsection{Interleukin (IL) $-1 \beta$}

Interleukin-1 $\beta$ gehört zu den proinflammatorischen Zytokinen, einer Gruppe von Proteinen, die vor allem auf Zellen der Immunantwort wirken. Hauptsächlich wird IL-1 $1 \beta$ von Monozyten freigesetzt. Die Vorform pro-IL-1 $\beta$ liegt im Zytosol der Zelle vor und wird durch aktivierte Caspase-1 zu aktivem IL-1 $\beta$ gespalten und freigesetzt. Dieser Vorgang wird durch endogene Pyrogene, bakterielle Lipopolysaccharide oder andere stimulierende Faktoren in Gang gesetzt. Proteinkomplexe wie das Inflammasom führen zu einer Aktivierung der ProCaspasen und somit auf direktem Weg zu einer IL-1ß Ausschüttung.

Systemisch bewirkt eine Erhöhung von IL-1 $\beta$ einen Anstieg der Thrombozyten, neutrophilen Granulozyten und Akute-Phase-Proteine und führt zur Ausbildung von Fieber. Außerdem kommt es zur Freisetzung von Prostaglandin E2, IL-6 und über eine ACTH-Erhöhung zur Freisetzung von Cortison.

Signifikant erhöhte Werte von IL-1 $\beta$ konnten in allen Entitäten der IIM nachgewiesen werden und legen aktuell den Schluss nahe, dass IL-1 $1 \beta$ eine wichtige Rolle in der Initiation der Erkrankungen spielen (De Paepe et al. 2009). 


\subsubsection{Interferon (IFN)-Y}

Interferon- $y$ ist ein Glykoprotein, das von Th1-Zellen nach Kontakt mit einem aktivierten Makrophagen freigesetzt wird. Die antimikrobielle Wirkung liegt zum einen in der Bildung von reaktiven Sauerstoffradikalen, zum anderen in der schnelleren Fusion von Lysosomen und Phagosomen der Makrophagen. Als starker Trigger der MHC-I Induktion spielt IFN- $y$ in der Pathogenese der inflammatorisch idiopathischen Myositiden eine große Rolle. Eine Hochregulation von IFN-y konnte in Muskelproben von IBM- und DM-Patienten gezeigt werden (de Paepe et al. 2009).

\subsubsection{Positivkontrollen}

\subsubsection{Immunzytochemische Positivkontrolle der Zytokinstimulation durch MHC-I-} Hochregulation

Der Major Histocompatibility Complex (MHC) ist eine Gruppe von Proteinen, die ein Teil des Immunsystems darstellen. Die MHC-Proteine sorgen für eine Erkennung von körpereigenen und körperfremden Strukturen.

Es wird zwischen drei verschiedenen MHC-Komplexen unterschieden, wobei der MHC-IKomplex die zelluläre Immunantwort aktiviert, der MHC-II-Komplex den humoralen Schenkel des Immunsystems anspricht und der MHC-III-Komplex zum angeborenen, humoralen Komplementsystem gehört.

MHC-I wird von allen kernhaltigen Zellen des Körpers exprimiert und an der Zelloberfläche präsentiert. Dort werden von der Zelle synthetisierte Peptide präsentiert. Im Fall einer gesunden Zelle werden also zelleigene Peptide präsentiert, was zu einer Selbsttoleranz führt. Ist die Zelle von einem Virusgenom befallen, werden körperfremde Proteine synthetisiert, prozessiert und an der Oberfläche präsentiert, wodurch es zu einer Bindung von zytotoxischen CD8 ${ }^{+}$T-Zellen kommt und die Apoptose ausgelöst wird.

Unter physiologischen Bedingungen wird die MHC-I Expression nach der Differenzierung der Myoblasten zu Myotuben herunterreguliert. Im Falle der IIMs ist MHC-I jedoch bei bis $\mathrm{zu} 3 / 4$ der Patienten überexprimiert und wird über Endoplasmic-Reticulum-Stress (ERStress) als Induktor des NFKB-Pfades angesehen (Ceribelli et al. 2017). 


\subsection{Ziele der Arbeit}

Muskelbiopsien von IBM Patienten weisen sowohl eine Akkumulation von degenerativen Proteinen wie $\beta$-Amyloid, $\alpha$-Synuclein und APO-E, als auch entzündliche Aspekte auf. Die Vermutung, dass das NLRP3-Inflammasom ein möglicher Bestandteil der inflammatorischen Kaskade der IBM-Pathogenese darstellt, legen die folgenden Aspekte nahe.

1. Als direkte Folge einer Aktivierung des NLRP3-ASC-Caspase-Komplexes wird vermehrt IL-1 $\beta$ freigesetzt.

2. In der Entstehung und Unterhaltung anderer idiopathisch inflammatorischer Myopathien spielen erhöhte IL-1 $\beta$ - Spiegel eine wichtige Rolle (Rawat et al. 2010).

3. Es konnte zusätzlich ein signifikanter Zusammenhang zwischen den IL-1 $\beta$-Spiegeln und dem Ausmaß an Akkumulation degenerativer Proteine festgestellt werden (Schmidt et al. 2017).

Da $\beta$-Amyloid sowohl Bestandteil des histologischen Erscheinungsbildes der IBM als auch ein bekannter Aktivator des NLRP3-Inflammasoms ist, könnten die Amyloidablagerungen sowohl Folge als auch Ursache einer möglichen NLRP3 Aktivierung darstellen.

Ziel dieser Arbeit ist es eine Regulation des Inflammasoms in Muskelzellen im entzündlichen Milieu zu untersuchen. Im nachfolgenden Schritt soll eine Regulation des Inflammasoms auf RNA-Ebene in Muskelgewebe von IIM-Patienten getestet werden. Vergleichend dazu ist es ein weiteres Ziel, Proben von Patienten mit erblichen Erkrankungen des Muskels auf eine Inflammasomregulation hin zu untersuchen. 


\section{Material und Methoden}

\subsection{Zelllinien}

Für die Vorexperimente wurde die immortalisierte Rhabdomyosarkomzelllinie CCL136 vom Institut für angewandte Zellkultur, München, Deutschland (im Folgenden Myoblasten genannt) und eine primäre Myotubenkultur verwendet. Die Proben der Primärkultur wurden bei unfallchirurgischen und orthopädischen operativen Eingriffen von humanen Spendern entnommen und in Kultur genommen. Alle Patienten wurden präoperativ über die Nutzung der Muskelproben im Rahmen der experimentellen Forschungsarbeit aufgeklärt. Ein positives Votum der Ethikkommission liegt vor.

Alle Zelllinien wurden bei $37^{\circ} \mathrm{C}$ und $5 \% \mathrm{CO}_{2}$ im Inkubator in feuchtem Milieu kultiviert. Sämtliche Arbeiten mit der Zellkultur wurden unter einer Sterilbank und mit autoklavierten Materialien vorgenommen. Alle Medien wurden vor Nutzung steril filtriert.

\subsubsection{Kultivierung}

Die Kultivierung der adhärenten Myoblastenlinie erfolgte in DMEM-Medium mit Zusatz von $10 \%$ FCS, 1 \% Penicillin/Streptomycin und $1 \%$ L-Glutamin. Die adhärente Primärzelllinie wurde in Skeletal Muscle Growth Medium kultiviert.

Um die Zellen von den Kulturflaschen zu lösen, wurden sie nach dem Waschen mit warmem 1xPBS für 5 Minuten mit 0,05\% Trypsin-EDTA inkubiert und mit dem doppelten Volumen an Medium resuspendiert. 
Tabelle 2) Verwendete Kulturmedien

\begin{tabular}{|l|l|}
\hline Medium/Supplement & Firma \\
\hline $\begin{array}{l}\text { Skeletal Muscle Cell Growth } \\
\text { Medium }\end{array}$ & PromoCell, PromoCell GmbH, Heidelberg, Deutschland \\
entiation-Medium & $\begin{array}{l}\text { Gibco, Life technologies Corporation by Thermo Fisher } \\
\text { Scientific, Massachusetts, USA }\end{array}$ \\
\hline DMEM & Biochrom GmbH, Berlin, Deutschland \\
\hline Penicillin/Streptomycin & $\begin{array}{l}\text { PAA laboratories Inc. by Thermo Fisher Scientific Massa- } \\
\text { chusetts, USA }\end{array}$ \\
\hline FCS (hitzeinaktiviert) & $\begin{array}{l}\text { Gibco, Life technologies Corporation by Thermo Fisher } \\
\text { Scientific, Massachusetts, USA }\end{array}$ \\
\hline L-Glutamin & $\begin{array}{l}\text { Gibco, Life technologies Corporation by Thermo Fisher } \\
\text { Scientific, Massachusetts, USA }\end{array}$ \\
\hline $0,05 \%$ Trypsin / EDTA & Lonza Group, Basel, Schweiz \\
\hline x-vivo &
\end{tabular}

\subsubsection{Kultivierung in Chamberslides/6-well-Platten}

Für Versuchsanordnungen wurden die Zellen in vorbeschriebener Weise in Suspension gebracht und mittels einer Neubauer-Zählkammer ausgezählt. Um eine genaue Bestimmung der vitalen Zelldichte zu erhalten, wurde die auszuzählende Probe vorher mit Tryphanblau versetzt.

Je nach Versuchsdauer und Kammergröße wurde eine Zelldichte zwischen $1 \times 10^{4}$ und $2,5 \times 10^{5}$ Zellen pro Kammer gewählt. Die Zellen wurden bis zu einer Konfluenz von 70-80 \% der Myoblasten oder der vollständigen Differenzierung der Primärzelllinie zu Myotuben in den Wellplatten belassen und mit dem üblichen Medium kultiviert.

Die Primärzelllinie wurde zunächst auf ein Differenzierungsmedium gewechselt, um die vollständige Ausdifferenzierung zu befördern. Dann erfolgte ein Waschschritt mit 1xPBS und die Stimulation der Zellen. 


\subsubsection{Zytokinstimulation}

Während der Experimentdauer wurden die Zellen in serumfreiem x-vivo belassen. Dem Medium wurden, bei ausreichender Konfluenz bzw. Differenzierung der Zellen, Zytokine über 24, 48 und 72 Stunden zugegeben.

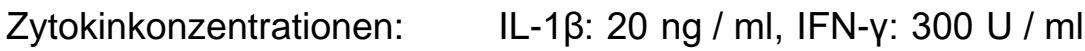

Das Beenden der Stimulation erfolgte mit Entnahme des Mediums. Nach einem Waschschritt mit warmem 1xPBS wurden die Zellen, wie im Folgenden beschrieben, fixiert.

\subsubsection{Fixieren der Zellen}

Nach Beenden der Stimulation mit einem Waschschritt wurde der Kammeraufsatz der Chamberslides nach Angaben des Herstellers entfernt. Eingelegte Coverslips wurden aus den Well-Platten entfernt.

Die Fixierung der Zellen auf den Objektträgern bzw. Coverslips erfolgte antikörperspezifisch mit $4 \%$ PFA und Methanol. Die Objektträger wurden zuerst 10 Minuten in warmem $4 \%$ PFA belassen. Danach erfolgte ein 5-minütiger Waschgang in warmem 1xPBS und 10 Minuten Inkubation in $-20{ }^{\circ} \mathrm{C}$ kaltem Methanol.

Da Methanol die Zellmembran perforiert, konnte auf eine zusätzliche Nutzung von TritonX verzichtet werden.

\subsection{Immunbiologische Methoden}

\subsubsection{Immunzytochemie}

Die fixierten Zellen wurden für eine indirekte Immunzytochemie 1 Stunde bei Raumtemperatur mit einer 1:1 Lösung aus $10 \%$ BSA und $100 \%$ Ziegen-Serum inkubiert.

Der Primärantikörper wurde in $1 \% \mathrm{BSA}$ verdünnt und über Nacht bei $4^{\circ} \mathrm{C}$ in einer feuchten Kammer inkubiert. Am nächsten Tag wurden die Objektträger dreimal 5 Minuten in warmem 1xPBS gewaschen und mit dem Sekundärantikörper 1 Stunde bei Raumtemperatur inkubiert. Dieser Ablauf wurde mit einem weiteren Primär- und Sekundärantikörper ebenso wiederholt, um eine Doppelfärbung zu erreichen. Anschließend wurde eine Kerngegenfärbung über 2 Minuten bei Raumtemperatur mit 4',6-Diamidin-2-phenylindol (DAPI) vorgenommen und die Objektträger mit Fluoromount-G (Biozol, München, Deutschland) eingedeckelt.

Sämtliche Antikörperinkubationen wurden in einer dunklen, feuchten Kammer vorgenommen. Die Objektträger wurden nach dem Färben dunkel und trocken verwahrt. 
Fotomikroskopische Aufnahmen wurden mit dem Axiovert 200M Mikroskop von Zeiss (Göttingen, Deutschland) gemacht.

Tabelle 3) Liste der verwendeten Primärantikörper

\begin{tabular}{|l|l|l|l|}
\hline $\begin{array}{l}\text { Spezifi- } \\
\text { tät }\end{array}$ & Hersteller & Spezies, ggf. Klon & $\begin{array}{l}\text { Inkubationszeit } \\
\text { und Verdünnung }\end{array}$ \\
\hline ASC & Abcam, Cambridge, UK & $\begin{array}{l}\text { Kaninchen polyklonal, IgG, } \\
\text { ASC } 2\end{array}$ & $\begin{array}{l}\text { über Nacht, } 4^{\circ} \mathrm{C}, \\
1: 500\end{array}$ \\
\hline MHC-I & $\begin{array}{l}\text { AbD Serotec, Bio-Rad La- } \\
\text { boratories, Kalifornien, } \\
\text { USA }\end{array}$ & Ratte monoklonal, IgG & $\begin{array}{l}\text { über Nacht, } 4{ }^{\circ} \mathrm{C}, \\
1: 200\end{array}$ \\
\hline NLRP3 & $\begin{array}{l}\text { Enzo Life Sciences Inc., } \\
\text { New York, USA }\end{array}$ & Maus monoklonal IgG & $\begin{array}{l}\text { über Nacht, } 4{ }^{\circ} \mathrm{C}, \\
1: 100\end{array}$ \\
\hline NLRP3 & $\begin{array}{l}\text { R\&D Systems Inc., Min- } \\
\text { nesota, USA }\end{array}$ & Maus monoklonal IgG & $\begin{array}{l}\text { über Nacht, } 4{ }^{\circ} \mathrm{C}, \\
1: 100\end{array}$ \\
\hline NLRP3 & Abcam, Cambridge, UK & $\begin{array}{l}\text { Maus monoklonal IgG, } \\
\text { Nalpy-3b }\end{array}$ & $\begin{array}{l}\text { über Nacht, } 4^{\circ} \mathrm{C}, \\
1: 100\end{array}$ \\
\hline NLRP3 & Abcam, Cambridge, UK & $\begin{array}{l}\text { Maus monoklonal IgG, } \\
\text { Nalpy-3a }\end{array}$ & $\begin{array}{l}\text { über Nacht, } 4{ }^{\circ} \mathrm{C}, \\
1: 200\end{array}$ \\
\hline NLRP3 & Abcam, Cambridge, UK & Kaninchen polyklonal, IgG & $\begin{array}{l}\text { über Nacht, } 4{ }^{\circ} \mathrm{C}, \\
1: 200\end{array}$ \\
\hline
\end{tabular}

Tabelle 4) Liste der verwendeten Primärantikörper

\begin{tabular}{|l|l|l|l|}
\hline Spezifität & Hersteller & Spezies, ggf. Klon & $\begin{array}{l}\text { Inkubationszeit und } \\
\text { Verdünnung }\end{array}$ \\
\hline anti-Maus & $\begin{array}{l}\text { Invitrogen by Thermo Fis- } \\
\text { her, Kalifornien, USA }\end{array}$ & Ziege, IgG & $\begin{array}{l}1 \mathrm{~h}, \text { Raumtempera- } \\
\text { tur, 1:500 }\end{array}$ \\
\hline anti-Ratte & $\begin{array}{l}\text { Invitrogen by Thermo Fis- } \\
\text { her, Kalifornien, USA }\end{array}$ & Ziege, IgG & $\begin{array}{l}1 \mathrm{~h}, \text { Raumtempera- } \\
\text { tur, 1:500 }\end{array}$ \\
\hline $\begin{array}{l}\text { anti-Kanin- } \\
\text { chen }\end{array}$ & $\begin{array}{l}\text { Invitrogen by Thermo Fis- } \\
\text { her, Kalifornien, USA }\end{array}$ & Ziege, IgG & $\begin{array}{l}1 \mathrm{~h}, \text { Raumtempera- } \\
\text { tur, 1:500 }\end{array}$ \\
\hline
\end{tabular}




\subsubsection{Western Blot}

\subsubsection{Proteinextraktion}

Für die Proteingewinnung wurden Myotubenkulturen, wie in 3.1.3. beschrieben, in 6-WellPlatten kultiviert und stimuliert. Zum Ende der Stimulation wurde das Medium entfernt und mit 1xPBS gewaschen. In jedes Well wurden $200 \mu$ RIPA-Puffer, versetzt mit Phosphostop, gegeben. Alle weiteren Schritte erfolgen auf Eis, außerhalb der sterilen Arbeitsbank. Das Zelllysat wurde in Mikroreaktionsgefäße überführt und 15 Minuten bei $4{ }^{\circ} \mathrm{C}$ und maximaler Geschwindigkeit zentrifugiert. Der Überstand wurde in autoklavierte Mikroreaktionsgefäße übernommen und die Proteinkonzentration mit Hilfe des Bradfordtests ermittelt.

\subsubsection{Bradfordtest}

Wie auch die Proteingewinnung, erfolgte das Pipettieren des Bradfordtests auf Eis. Dazu wurden je $50 \mu \mathrm{l}$ BSA-Proteinstandardproben in aufsteigender Konzentration von 0 bis $500 \mu \mathrm{g} / \mathrm{ml}$ in eine 96-Well-Platte pipettiert. Zusätzlich wurden die Proteinproben (1 $\mu \mathrm{l}$ auf $49 \mu \mathrm{l}$ Wasser) aufgetragen. Zuletzt wurden jeweils $150 \mu \mathrm{l}$ Bradfordreagenz (Bio-Rad Protein-Assay 1:50.000) hinzugegeben. Mittels Extinktion bei einer Wellenlänge von $595 \mathrm{~nm}$ erfolgte die Bestimmung der Proteinkonzentration.

\subsubsection{SDS-Gelelektrophorese}

Um die Proteinproben in einem Polyacrylamidgel der Größe nach auftrennen zu können, mussten diese mit einem negativ geladenen Puffer (Lämmli) in einer 1:6 Verdünnung 5 Minuten bei $95{ }^{\circ} \mathrm{C}$ aufgekocht werden. Dieser Schritt diente der Denaturierung der Sekundär- und Tertiärstruktur der Proteine. Die denaturierten Proteine wandern durch die negative Ladung innerhalb eines Gels zur angeschlossenen Anode. Dabei ist die Laufgeschwindigkeit abhängig von der Proteingröße. Neben der Proteingröße ist auch die Acrylamidkonzentration des Gels entscheidend für die Laufgeschwindigkeit der Proteine. Das Gel wurde zweiphasig aufgebaut, wobei die obere Phase das Sammelgel bildete. Dieses umgab Ladetaschen, die zur Konzentrierung der aufgetragenen Proben dienten. Die untere Phase stellte das Trenngel dar, in welchem die Proteine der Größe nach aufgetrennt wurden. Durch einen $\mathrm{pH}$-Unterschied der beiden Gele kam es vor dem Übertritt in das Trenngel zu einer Konzentrierung der Proteine und einem gleichmäßigen Lauf der Proteinprobe.

Das Elektrophoresegel wurde zwischen zwei Glasplatten gegossen. Zuerst erfolgte das Gießen des Trenngels bis circa $2 \mathrm{~cm}$ unterhalb der oberen Glaskante. Um einen sauberen 
Abschluss des Gels zu erreichen, wurde es mit einer dünnen Schicht Methanol bedeckt. Dieses wurde nach Abhärten des Trenngels abgegossen und das Sammelgel auf das Trenngel gegossen. Vor dem Aushärten wurde ein Kamm mit zehn Platzhaltern eingesetzt. Nach dem vollständigen Aushärten beider Gelphasen wurde es in eine Elektrophoresekammer eingesetzt und mit Elektrophoresepuffer aufgefült. Nachdem der Kamm entfernt und die entstandenen Taschen mit Puffer freigespült wurden, konnten sie mit dem Precision Plus Protein Standard (Bio-Rad Laboratories, Kalifornien, USA) als Größenmarker und den vorbereiteten Proteinproben beladen werden.

Im Folgenden wurden die Proben bei 100 Volt bis zu 2 Stunden aufgetrennt.

\subsubsection{4. Übertragen der aufgetrennten Proteine auf PVDF-Membran}

Nach dem Auftrennen in dem Gel wurden die Proteine in einer Blotkammer, mittels Wetblot-Verfahren, auf eine methanolaktivierte Polyvinylidenfluorid (PVDF)-Membran übertragen.

Dazu wurde eine Blotkammer von der Anodenplatte aus aufgeschichtet. Auf die Anodenplatte wurde ein in Puffer getränkter Schwamm aufgelegt. Darauf folgten drei puffergetränkte Blotpapiere und das Gel. Auf das Gel wurde die methanolaktivierte und puffergetränkte PVDF-Membran luftblasenfrei aufgelegt. Darauf wiederum folgten Schichten von drei Blotpapieren und einem puffergetränkten Schwamm. Als Abschluss wurde die Kathodenplatte aufgelegt und alles mit Druck aufeinander gespannt.

Die Blotkammer wurde in einem Transferpuffer mit einem pH von 8,3 bei 110 Volt 1,5 Stunden geblottet. Um eine Überhitzung und ein Verbrennen der PVDF-Membran zu verhindern, wurde der Transferpuffer mit einem Kühlakku abgekühlt.

Im Verlauf der Doktorabeit wurde als Blotverfahren das iBlot 2 Dry Blotting System von Invitrogen, Thermo Fisher Scientific, Kalifornien, USA, genutzt. Sämtliche Blotschritte wurden gemäß Verfahrensanweisung des Herstellers durchgeführt. 
Tabelle 5) Verwendete Pufferlösungen

\begin{tabular}{|ll|}
\hline $10 x$ Elektrophoresepuffer & \\
\hline $250 \mathrm{mM}$ Tris & $30,24 \mathrm{~g}$ \\
$1,9 \mathrm{M}$ Glycin & $142,5 \mathrm{~g}$ \\
$1 \%$ SDS & $10 \mathrm{~g}$ \\
$\mathrm{H} 2 \mathrm{O}$ & ad $1 \mathrm{~L}$ \\
\hline $10 \mathrm{x}$ Transferpuffer & $30,24 \mathrm{~g}$ \\
\hline 250 mM Tris & $144 \mathrm{~g}$ \\
1,92 M Glycin & ad $1 \mathrm{~L}, \mathrm{pH} 8,3$ einstellen \\
$\mathrm{H} 2 \mathrm{O}$ & \\
$20 \%$ Methanol für den $1 \times$ Ansatz
\end{tabular}

\subsubsection{Immunchemischer Nachweis der Proteinbanden}

Das Blocken der Membran erfolgte mit $5 \%$ BSA/TBS-Tween 0,1 \% über eine Stunde bei Raumtemperatur, um unspezifische Antikörperbindungen $\mathrm{zu}$ verhindern. Der Primärantikörper wurde in der Blocksolution verdünnt und über Nacht bei $4{ }^{\circ} \mathrm{C}$ inkubiert. Nach 5x 5 Minuten waschen mit TBS-Tween wurde der Sekundärantikörper in $5 \%$ BSA/TBS-Tween 0,1\% verdünnt und 1,5 Stunden bei Raumtemperatur inkubiert.

Nach erneutem Waschen mit TBS-Tween wurde die Membran mit Pierce ECL Western Blotting Substrate (Thermo Scientific, Rockford, USA bedeckt und entwickelt. Aufnahmen der angefärbten PVDF-Membranen wurden mit einem Fusion FX (Vilber Lourmat GmbH, Eberhardzell, Deutschland) gemacht und mit dem zugehörigen Programm Vision Capt (Analis, Suarlee, Belgien) dargestellt. 
Tabelle 6) Liste der genutzten Primärantikörper des Western Blots

\begin{tabular}{|l|l|l|l|}
\hline Spezifität & Hersteller & Spezies ggf. Klon & $\begin{array}{l}\text { Inkubation und Ver- } \\
\text { dünnung }\end{array}$ \\
\hline NLRP3 & $\begin{array}{l}\text { Abcam, Cambridge, } \\
\text { UK }\end{array}$ & $\begin{array}{l}\text { Kaninchen, } \\
\text { polyklonal, IgG }\end{array}$ & $\begin{array}{l}\text { über Nacht, } 4{ }^{\circ} \mathrm{C}, \\
1: 1000\end{array}$ \\
\hline ASC & $\begin{array}{l}\text { Abcam, Cambridge, } \\
\text { UK }\end{array}$ & $\begin{array}{l}\text { Kaninchen, } \\
\text { polyklonal, IgG }\end{array}$ & $24 \mathrm{~h}$ bei $4^{\circ} \mathrm{C}$ \\
\hline$\beta$-Actin & $\begin{array}{l}\text { Sigma-Aldrich, } \\
\text { St.Louis, USA }\end{array}$ & $\begin{array}{l}\text { Maus, monoklonal, } \\
\text { IgG }\end{array}$ & $1 \mathrm{~h}, \mathrm{RT}, 1: 5000$ \\
\hline
\end{tabular}

Tabelle 7) Liste der genutzten Sekundärantikörper des Western Blots

\begin{tabular}{|l|l|l|l|}
\hline Spezifität & Hersteller & Spezies ggf. Klon & $\begin{array}{l}\text { Inkubationszeit und } \\
\text { Verdünnung }\end{array}$ \\
\hline Anti-Maus & $\begin{array}{l}\text { Jackson Immuno } \\
\text { Research Laborato- } \\
\text { ries Inc., Baltimore, } \\
\text { USA }\end{array}$ & Ziege, polyklonal, & $1 \mathrm{~h}, \mathrm{RT}, 1: 5000$ \\
\hline Anti-Kaninchen & $\begin{array}{l}\text { Jackson Immuno } \\
\text { Research Laborato- } \\
\text { ries Inc., Baltimore, } \\
\text { USA }\end{array}$ & Ziege, polyklonal, & $1 \mathrm{~h}, \mathrm{RT}, 1: 5000$ \\
\hline
\end{tabular}

\subsubsection{Ponceau-Färbung}

Die Membran wurde, als Positivkontrolle der gleichmäßigen und vollständigen Proteinübertragung, mit Ponceau-S Lösung unspezifisch und reversibel angefärbt. Mit 1xTBS-Tween wurde die Ponceau-S Färbung wieder abgewaschen.

\subsubsection{Coomassie-Brillant-Blau-Färbung}

Den Nachweis für eine vollständige Übertragung der Proteine aus dem Gel auf die PVDFMembran lieferte eine Coomassie-Färbung des Gels. Der Farbstoff bindet unspezifisch an basische Seitenketten der Aminosäuren. 


\subsection{Molekularbiologische Methoden}

\subsubsection{RNA-Extraktion}

\subsubsection{RNA-Extraktion aus Zellkultur}

Für die Extraktion von RNA wurden Myotuben in 6-Well-Platten gezüchtet und mit Zytokinen über 24 Stunden stimuliert. Zur Beendigung der Zellstimulation wurde das X-vivo aus den Wellplatten entnommen. Gleichzeitig bewachsene Coverslips wurden aus den Wells entfernt und für eine immunzytochemische Färbung mit 4 \% PFA und Methanol fixiert.

In jedes Well wurden $350 \mu \mathrm{l}$ RLT-Lysisbuffer, versetzt mit $1 \% \beta$-Mercaptoethanol, pipettiert und 30 Minuten bei Raumtemperatur inkubiert.

Das Zelllysat wurde in autoklavierte Mikroreaktionsgefäße aufgenommen und 3 Minuten bei maximaler Geschwindigkeit und $4{ }^{\circ} \mathrm{C}$ zentrifugiert. Der Überstand wurde wiederum in neue Mikroreaktionsgefäße überführt. Jede Probe wurde mit $700 \mu \mathrm{l} 70 \%$ Ethanol versetzt. Alle folgenden Arbeitsschritte erfolgten gemäß der Herstellerangabe des RNeasy Mini Kit (Quiagen, Hilden Germany). Die Zentrifugationsschritte verliefen ausnahmslos bei Raumtemperatur, 15 Sekunden Dauer und bei 9000 g. Zuerst wurde das Zelllysat-Ethanolgemisch über einer Säule zentrifugiert. Der Durchfluss wurde jedes Mal verworfen. Daraufhin wurden $700 \mu \mathrm{l}$ RW1-Puffer auf die Säule gegeben und erneut zentrifugiert. Darauf folgten zwei Waschschritte mit $500 \mu \mathrm{l}$ RPE-Puffer. Anschließend wurde die Membran 2 Minuten bei $9000 \mathrm{~g}$ zentrifugiert, um diese zu trocknen. Die RNA wurde mit $33 \mu \mathrm{l}$ RAse freiem Wasser eluiert. Dazu folgte ein letzter Zentrifugationsschritt bei $10.000 \mathrm{~g}$ und 1 Minute Dauer.

Die RNA-Konzentration wurde mit einem Nanodrop Spektralphotometer gemessen. Dabei kann die Konzentration durch Extinktion bei $260 \mathrm{~nm}$ in einem kleinen Volumen ( $1 \mu \mathrm{l}$ Probe) bestimmt werden.

Gelagert wurde die RNA bei $-80^{\circ} \mathrm{C}$.

\subsubsection{RNA-Extraktion aus Gewebe}

Zur Extraktion von RNA aus den Patientenbiopsien wurde das Gewebe mit $350 \mu$ Trizol in Beads Röhrchen homogenisiert und mit Chloroform versetzt. Nachfolgende Schritte wurden mit dem RNeasy mini Kit von Quiagen (Hilden, Deutschland), wie in 3.3.1. beschrieben, gemäß Verfahrensanweisung vorgenommen. 


\subsection{2. cDNA-Synthese}

Die Synthese der komplementären DNA aus der vorher isolierten mRNA wurde mit dem SuperScript II kit von Invitrogen vorgenommen. Dabei wurde mittels Oligo-dt-Nukleotiden und einer RNA- abhängigen DNA-Polymerase ein zur mRNA komplementärer cDNA Strang synthetisiert. Eine DNA-abhängige DNA-Polymerase synthetisiert im Weiteren einen komplementären DNA-Strang, sodass letztendlich ein DNA-Doppelstrang vorliegt. Da als Ausgangsmaterial eine prozessierte RNA genutzt wurde, enthält der DNA-Doppelstrang keine Introns.

\subsection{3. $\mathrm{qRT}$-PCR}

Bei der qRT-PCR (quantitative Echtzeit-Polymerase-Kettenreaktion) erfolgt eine fluoreszenzbasierte quantitative Bestimmung von Nukleinsäureprodukten mit dem Quant Studio System von Applied Biosystems. Mit Hilfe eines TaqMan-Sonden Systems (Applied Biosystems, Kalifornien, USA) wurde die Replikation der Nukleinsäuren gemessen und ausgewertet. Primer wurden von Dharmacon (Colorado, USA) bezogen. Nach einer Firmenumstellung wurde auf TaqMan Gene Expression Assays von Applied Biosystems by Thermo Fisher Scientific (Massachusetts, USA) zurückgegriffen.

Der Ansatz für eine Bestimmung der mRNA Expression bestand aus $10 \mu \mathrm{l}$ MasterMix, $1 \mu \mathrm{l}$ cDNA, $8 \mu$ l RNAse freiem Wasser und $1 \mu$ Primer. Als endogene Kontrolle und Vergleichswert wurde die Expression von GAPDH verwendet. Jede Probe wurde als Triplikat eingesetzt.

Tabelle 8) PCR-Ablauf:

\begin{tabular}{|l|l|l|}
\hline Arbeitsschritt & Temperatur $\left[{ }^{\circ} \mathrm{C}\right]$ & Dauer [min] \\
\hline Initialisierung & 50 & 2 \\
\hline Hitzeaktivierung & 95 & 10 \\
\hline Denaturierung & 95 & 0,25 \\
\hline Hybridisierung/Elongation & 60 & 1 \\
\hline
\end{tabular}

\subsection{Statistische Auswertung}

Die statistische und graphische Auswertung der PCR-Ergebnisse erfolgte mit Hilfe des Graphpad Prism 6 Programmes (San Diego, USA). Zuvor wurden Ausreißer der Triplikate mit dem Ausreißertest nach Grubbs von Graphpad ermittelt und gegebenenfalls aus der Wertung genommen. Über Column statistics erfolgte zuerst der Test auf die Normalverteilung der Werte mittels D`Agostino \& Pearson omnibus normality test. Konnte 
eine Normalverteilung nachgewiesen werden, wurde die Signifikanz der Ergebnisse mit dem ungepaarten students t-Test berechnet. Bei fehlender Normalverteilung wurde der Mann-Whitney-Test angewendet, um eine Signifikanzbestimmung vorzunehmen.

Eine Auswertung der immunzytochemischen Färbungen und Proteinbanden des Western Blots erfolgte mittels Greyscale-Analyse über Image J 1.46 von Wayne Rasband (National Institute of Health, USA).

Für die schriftliche Ausarbeitung der Arbeit wurden Microsoft Word 2016 und Microsoft Excel verwendet. Präsentationen wurden über Microsoft Power Point 2016 erstellt. 


\section{Ergebnisse}

\subsection{Einleitung}

Um herauszufinden ob Myotuben in einem entzündlichen Milieu wie dem der IBM eine Regulation des Inflammasomkomplexes zeigen, wurden die zuvor beschriebenen immunzytochemischen und molekularbiologischen Methoden angewandt. Im Folgenden werden die Nachweismethoden einzeln betrachtet. Erweiternde Untersuchungen von Patientenproben werden zum Abschluss aufgeführt.

\subsection{Proteinexpression von NLRP3 in Muskelzellen nach inflammatorischem Zellstress}

\subsubsection{Proteinnachweis mittels Immunzytochemie}

Mögliche Auswirkungen des inflammatorischen Milieus auf Proteinebene in Myotuben wurden mit immunzytochemischen Nachweismethoden untersucht. Hierzu wurden die primären Myotubenkulturen dem proinflammatorischen Milieu von IL-1 $\beta$ und IFN-y über 24 Stunden ausgesetzt und wie bereits beschrieben auf Objektträgern fixiert. Anschließend wurde mit Hilfe spezifischer Antikörper das Inflammasomprotein NLRP3 markiert und mittels fluoreszenzmarkierter Sekundärantikörper dargestellt. Gleichzeitig erfolgte bei jedem Experiment die Färbung des MHC-I-Komplexes. Eine Hochregulation dieses Komplexes wurde hier als Positivkontrolle der Stimulation gewertet.

Die visuelle Auswertung erfolgte am Fluoreszenzmikroskop. Um eine statistische Aussage über die Intensitätszunahme des Fluoreszenzsignals treffen zu können, wurden repräsentative Aufnahmen der verschiedenen Experimentbedingungen gemacht. Die Signalintensität wurde über das Bearbeitungsprogramm ImageJ gemessen. Für die statistische Auswertung wurde zuvor das unspezifische Hintergrundsignal mit Hilfe eines visuell definierten Threshold sowohl bei Kontrollproben als auch bei den stimulierten Proben subtrahiert.

In die Auswertung wurden sechs Experimente ausgehend von Myotuben sechs unterschiedlicher Muskelspender einbezogen. Zur weiteren Quantifizierung wurden zusätzlich Experimentdauern von 48 und 72 Stunden gewählt. Hier konnten die Versuche mit den Proben der sechs verschiedenen Patienten reproduziert und analysiert werden. Für die Stimulationsdauer von 72 Stunden konnten nur vier Experimente in die Auswertung einbezogen werden.

Es zeigte sich eine signifikante Hochregulation des MHC-I-Komplexes unter Stimulation mit IL-1 $\beta$ und IFN- $y$ zu allen Zeitpunkten. Signifikanzniveaus von $p=0,0087$ für $24 h, p=0,041$ für $48 \mathrm{~h}$ und $\mathrm{p}=0,028$ wurden durch den Mann-Whitney-Test bei fehlender Normalverteilung 
der Ergebnisse errechnet. Das Inflammasom NLRP3 wurde zu jedem Zeitpunkt im Vergleich zur unstimulierten Kontrolle hochreguliert. Eine signifikante Hochregulation ließ sich zu keinem Zeitpunkt ermitteln. Insgesamt steigt die mittlere Signalintensität des NLRP3Fluoreszenzsignals in der Kontrollgruppe mit zunehmender Zeit leicht an und zeigt in den Stimulationsproben zuerst einen Anstieg von 24 auf 48 Stunden und bei 72 Stunden wiederum einen Abfall auf ein Niveau zwischen dem von 24 und 48 Stunden. Im Vergleich von Stimulation zur Kontrolle liegt die Hochregulation bei 24 Stunden bei einem Faktor von 2,2, bei 48 Stunden bei 2,5 und bei 72 Stunden bei einem Faktor von 1,3.

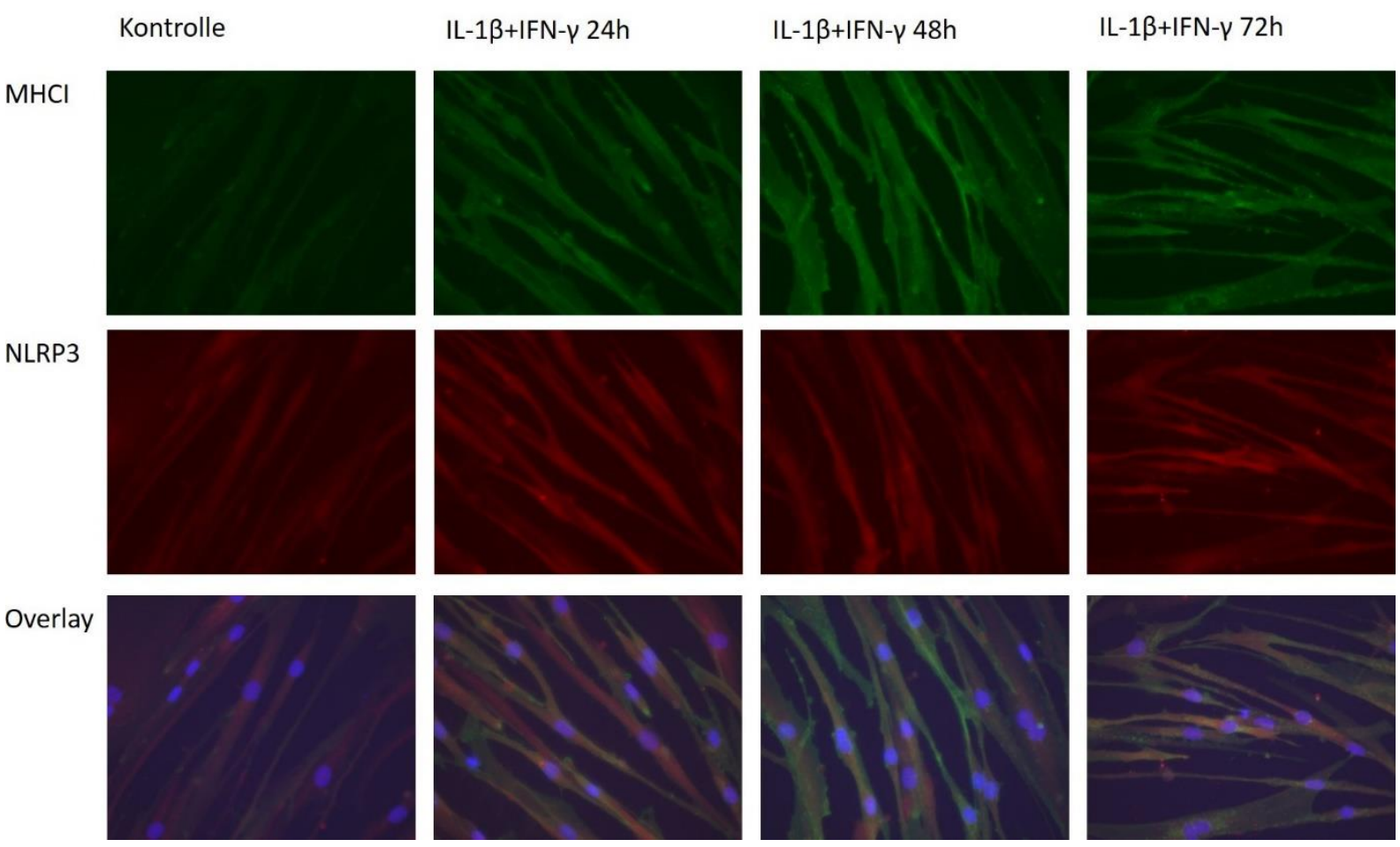

Abbildung 2) Fluoreszenzsignal der Immunzytochemie von NLRP3 und $\mathrm{MHCl}$ in Myotuben ohne Zytokinstimulation und unter Zytokinstimulation für 24, 48 und 72 Stunden 

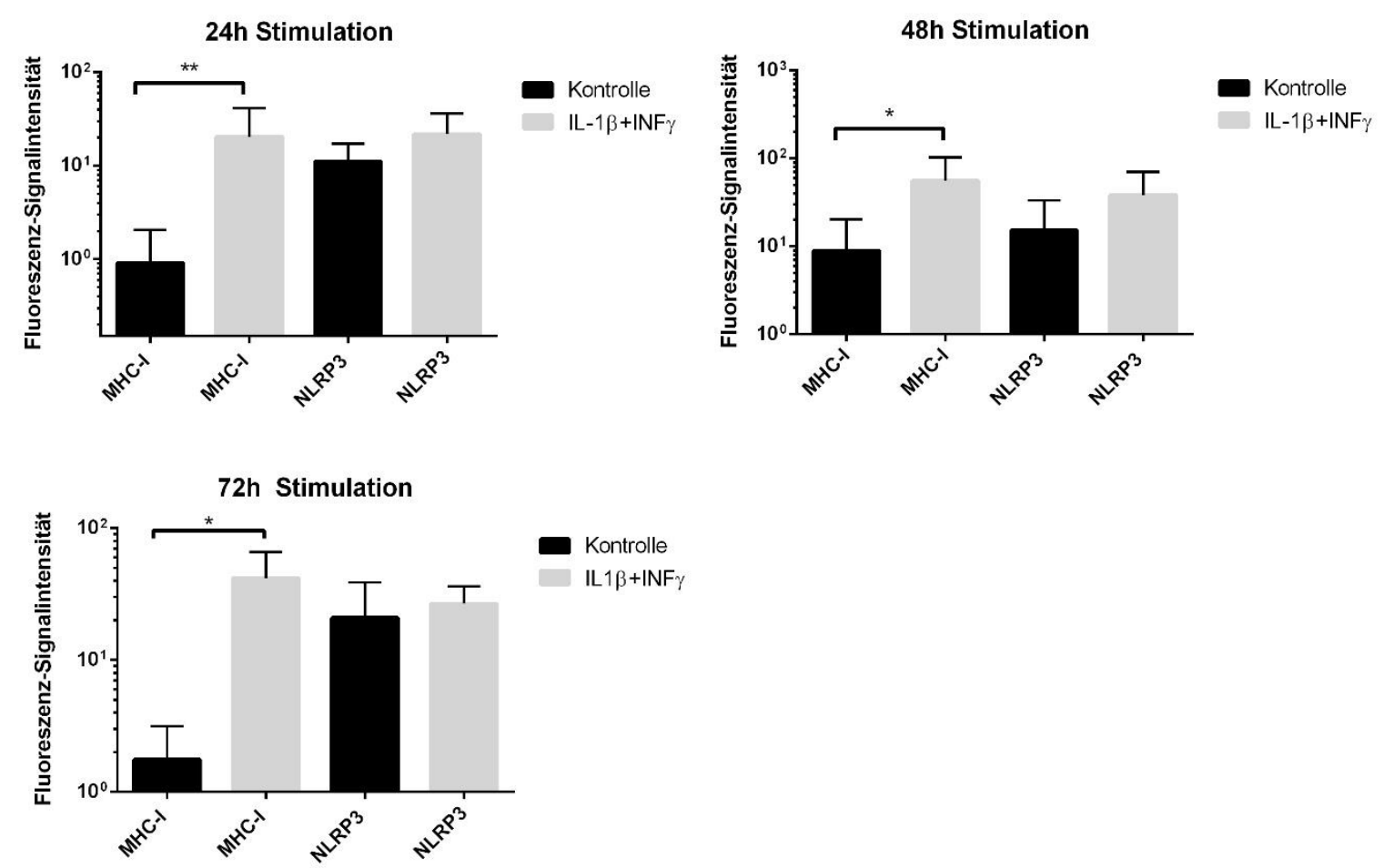

Abbildung 3) Grafische Darstellung der Signalintensität von MHCl und NLRP3 ohne und mit 24-, 48- und 72-stündiger Stimulations dauer. Es konnte jeweils eine signifikante Intensitätszunahme der MHC-I Färbung gezeigt werden. Eine Signalintensitätszunahme der NLRP3-Färbung von Kontrolle zur Stimulation ist zu allen untersuchten Zeitpunkten belegbar.

\subsubsection{Proteinnachweis mittels Western Blot}

Zusätzlich wurden Proteinproben von stimulierten Myotubenkulturen extrahiert und mittels Gelelektrophorese aufgetrennt. Vergleichend wurden unstimulierte Kontrollproben und eine Positivkontrolle aufgetragen. Für jede Probe wurden jeweils $30 \mu \mathrm{g}$ Proteinlysat verwendet. Durch das Western Blot-Verfahren wurden die aufgetrennten Proteinproben auf eine PVDFMembran übertragen und mit spezifischen Antikörpern angefärbt.

Die Auswertung der Aufnahmen erfolgte über eine Grauskalenanalyse mittels ImageJ.

Es wurden verschiedene Primärantikörper gegen das NLRP3-Protein ausgetestet und aufgrund nicht ausreichender Spezifität nicht weiterverwendet. Ausgewertet und gezeigt werden in dieser Arbeit nur Daten, die mit dem polyklonalen Primärantikörper der Firma Abcam erhoben wurden. Aufgrund mangelnder Spezifität wurde ebenfalls auf eine Verwendung des ASC-Antikörpers verzichtet. Dieser zeigte weder in der Anfärbung von ICC noch von Proteinbanden im Western Blot das durch den Hersteller vorhergesagte Verhalten. Vielmehr zeigte sich eine unselektives Signal vieler Strukturen in der Immunzytochemie bzw. wechselnde Anfärbung polyklonaler Banden im Western Blot. Erhobene Daten und Grafiken mit diesem Antikörper werden nicht dargestellt. 
Repräsentativ wird ein Western Blot mit Bandenanfärbung durch den NLRP3-Antikörper auf Höhe von 117 kDa und der endogenen Beladungskontrolle $\beta$-Actin auf Höhe von 42 kDa gezeigt (Abbildung 4). Die Ergebnisse der Proteinregulation konnten in sechs voneinander separierten Experimenten reproduziert werden. Dargestellt wurde die Signalintensität der NLRP3-positiven Bande relativ zur Endogenkontrolle $\beta$-Actin (Abbildung 5). In der statistischen Auswertung zeigte sich keine Normalverteilung der Ergebnisse. Mit einem $p-$ Wert von 0,026 im Mann-Whitney-Test wurde das Signifikanzniveau von $\alpha<0,05$ erreicht.

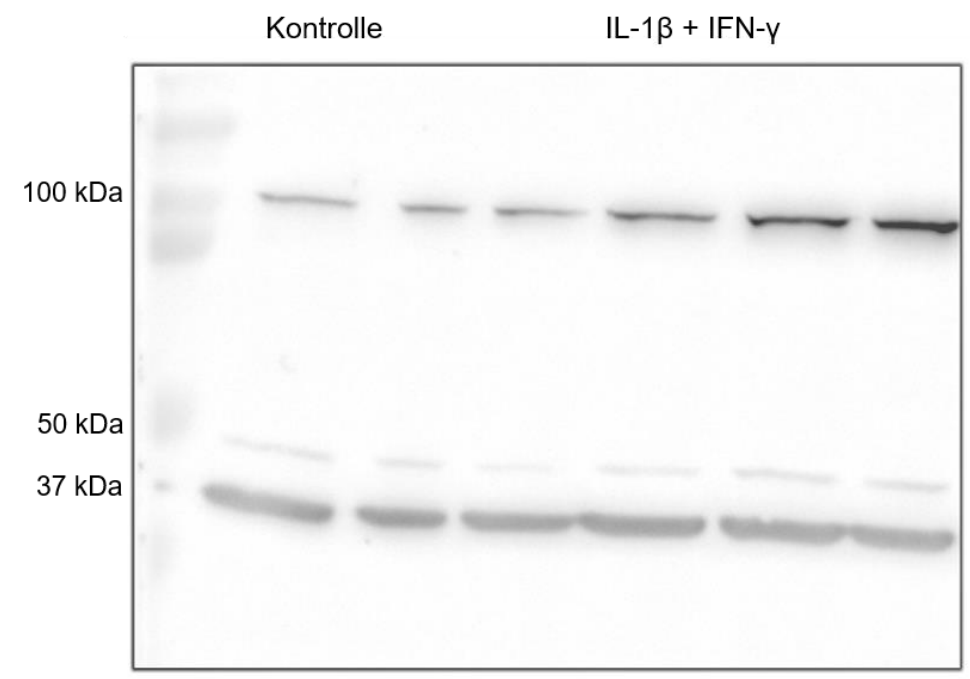

Abbildung 4) Repräsentative Western Blot-Aufnahme. Aufgetragen sind drei Kontrollproben und drei Proben nach 24-stündiger Stimulation mit IL-1 $\beta$ und IFN- $(30 \mu g$ Proteinlysat, Membrananfärbung mit polyklonalem NLRP3-AK (Bandenhöhe $118 \mathrm{kDa}$ ), Endogenkontrolle mit AK gegen $\beta$-Actin (Bandenhöhe $42 \mathrm{kDa})$ )

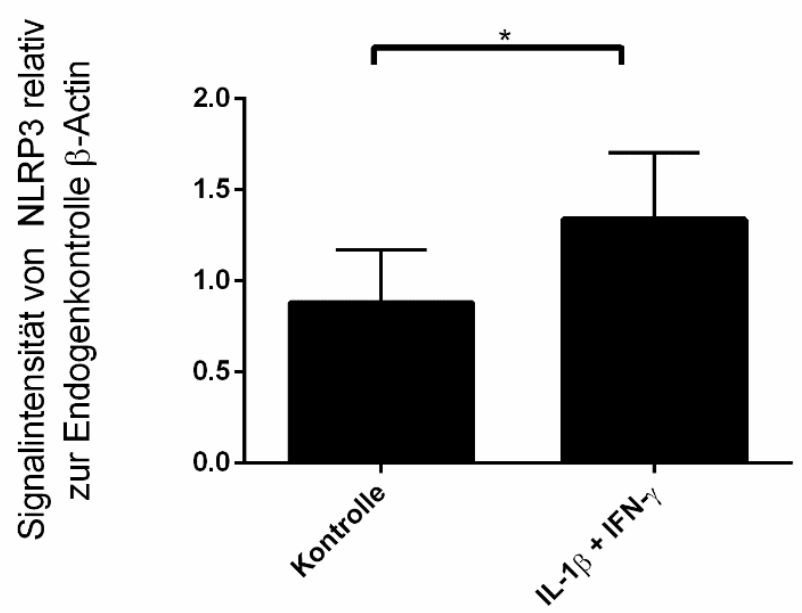

Abbildung 5) Signalintensität der Proteinbanden des NLRP3-Inflammasoms im Western Blot ohne und mit 24-stündiger Stimulation. Es zeigte sich eine signifikante Hochregulation auf Proteinebene $(n=6$, Mann-Whitney-Test, p-value 0,026) 


\section{3. mRNA-Expression in gesunden Muskelzellen nach inflammatorischen}

Stimuli

Um die Ergebnisse eines vorangegangenen Micro-Arrays in Bezug auf die Genregulation einiger inflammatorischer Gene weiter zu untersuchen, wurden molekularbiologische Untersuchungen an in vitro kultivierten und stimulierten Myotuben durchgeführt. Hierfür wurden die oben beschriebenen Myoblasten und primären Myotuben mittels proinflammatorischer Zytokine über 24 Stunden einem Zellstress ausgesetzt. Im Anschluss erfolgte die Expressionsanalyse der Chemokine CCL8, CCL20, CXCL10, CXCL11, der GTPasen GBP1 und GBP5 sowie der Inflammasomproteine NLRP3 und NLRC5.

Mittels quantitativer real time PCR wurden Expressionen der zu untersuchenden Gene in Relation zu der Endogenkontrolle GAPDH gemessen. Im zweiten Schritt wurden Expressionswerte von stimulierten Myotubenproben mit unbehandelten Kontrollproben verglichen.

Insgesamt wurden auf diese Weise Daten von jeweils drei humanen Muskelproben gesammelt, reproduziert und im Anschluss gepoolt.

Es zeigte sich ein inflammatorischer Effekt auf alle untersuchten Zielgene im Vergleich der experimentellen Stimulation gegen die unbehandelten Kontrollen. Bei einer Versuchsdauer von 24 Stunden war jeweils eine signifikante Hochregulation aller untersuchten Marker zu beobachten.

Im Folgenden sind die qRT-PCR-Ergebnisse als relative Expression zur Endogenkontrolle GAPDH dargestellt. Aufgetragen wurde der Mittelwert mit Standardfehler (Abbildung 6-8).

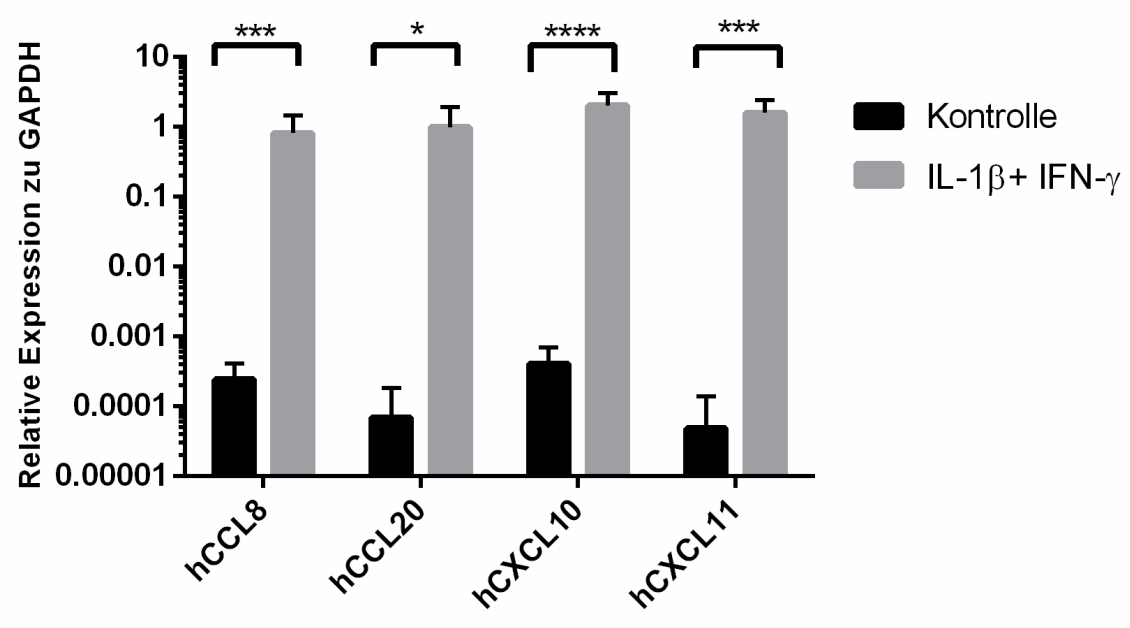

Abbildung 6) Relative Expression der Chemokine zur Endogenkontrolle GAPDH. Es zeigte sich eine signifikante Hochregulation der Chemokine im Vergleich von Kontrollproben zur Stimulation $(n=8$, students t-test/Mann-Whitney-Test, Signifikanzniveaus ${ }^{*} p<0,05,{ }^{* * *} p<0,001,{ }^{* * * *} p<0,0001$ ) 


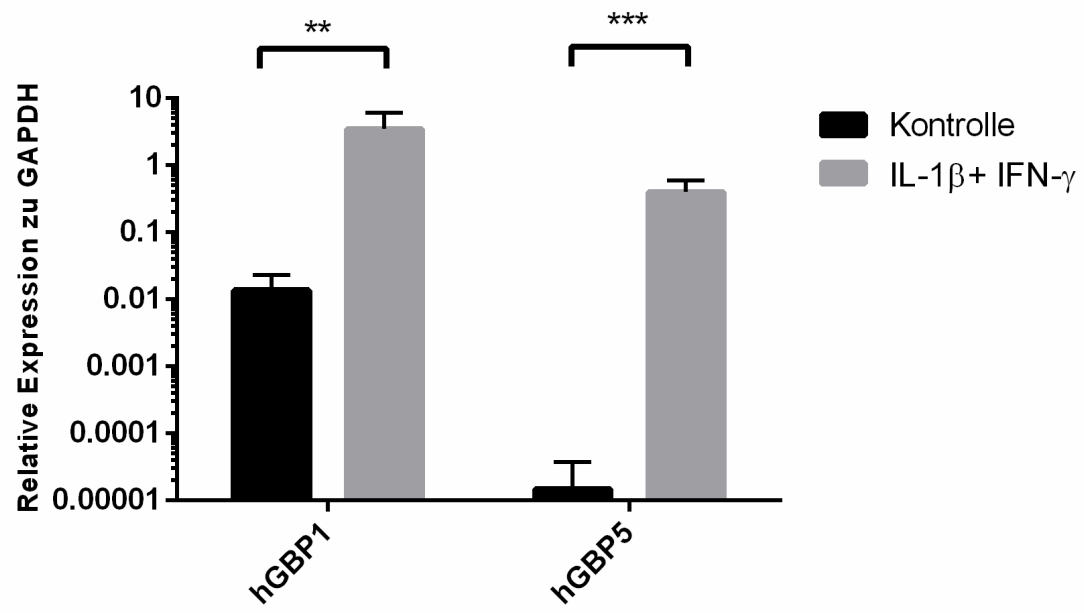

Abbildung 7) Relative Expression der GBP-Proteine zu GAPDH mit signifikanter Hochregulation der mRNA von GBP1 und GBP5 im Vergleich zu der unbehandelten Kontrollgruppe ( $n=8$, students ttest/Mann-Whitney-Test, Signifikanzniveaus ${ }^{* *} p<0,01,{ }^{* * *} p<0,001$ )

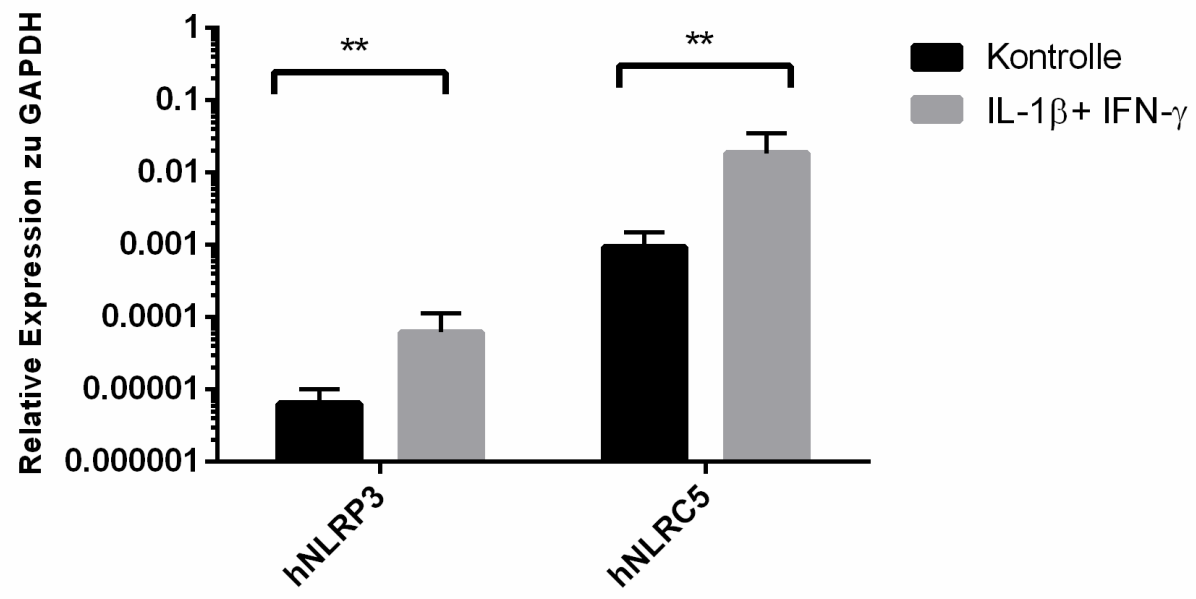

Abbildung 8) mRNA-Expression von NLRP3 und NLRC5 relativ zur Endogenkontrolle GAPDH. Im Vergleich zur Kontrollgruppe stellte sich eine signifikante Hochregulation der mRNA beider Parameter unter Stimulationsbedingungen dar $\left(n=8\right.$, students t-test, Signifikanzniveaus $\left.{ }^{* *} p<0,01\right)$.

\section{4. mRNA-Expression in Muskelproben von Myositispatienten}

Ergänzend zu den in vitro Experimenten wurden molekularbiologische Untersuchungen an Muskelbiopsien von Patienten durchgeführt. Als Kontrollgruppe dienten biopsierte Patienten ohne inflammatorische Veränderungen in der histologischen Beurteilung. Vergleichend wurden Analysen von Patienten mit der klinischen und pathologischen Diagnose der IBM 
vorgenommen. Weiterhin erfolgte eine RNA-Expressionsanalyse von Muskelproben, welche Patienten mit der Diagnose einer Dermatomyositis, Polymyositis, Nekrotisierenden Myopathie und mit hereditären Muskeldystrophien einschloss.

Ziel war es, mindestens zehn Patientenproben aus dem Patientenkollektiv der Universitätsmedizin Göttingen pro Erkrankungsentität molekularbiologisch zu untersuchen.

Letztendlich konnten Proben von insgesamt 68 Patienten untersucht werden. Die gewünschte Mindestzahl von zehn Proben pro Erkrankungsentität wurde in jedem Fall erreicht. Für die Gruppierungen der IBM, der Kontrolle und der PM konnte sie sogar überschritten werden. Im Gesamten zeigt sich eine annähernde Gleichverteilung auf Proben von männlichen und weiblichen Patienten sowie das mittlere Alter bei Biopsienahme.

Um die Übersichtlichkeit zu wahren, wird eine genaue Differenzierung über die Geschlechterverteilung und das Patientenalter bei Biopsie tabellarisch in Tabelle 9 dargestellt. Biopsiezeitpunkt war im Großteil der Fälle Zeitpunkt der Diagnosestellung einer der Erkrankungsgruppen. In Hinsicht auf die Kontrollgruppe erfolgten Biopsien bei unspezifischen Myopathien, Muskelkatergefühl oder Muskelschwäche. Im Rahmen der histopathologischen Untersuchung ließen sich keine Veränderungen der Muskelproben, vor allem in Bezug auf Veränderungen im Sinne einer Myositis, finden.

Tabelle 9) Auflistung der eingeschlossenen Patientenproben nach Erkrankung, Geschlecht und Altersverteilung (gerundet) bei Biopsie.

\begin{tabular}{|l|l|l|l|l|}
\hline & n gesamt & $\begin{array}{l}\text { Anteil } \\
\text { männlich (\%) }\end{array}$ & $\begin{array}{l}\text { Anteil } \\
\text { weiblich (\%) }\end{array}$ & $\begin{array}{l}\text { Mittleres } \\
\text { Biopsiealter } \\
\text { in Jahren }\end{array}$ \\
\hline Gesamt & 68 & 56 & 44 & 54 \\
\hline Kontrolle & 11 & 36 & 64 & 48 \\
\hline IBM & 14 & 79 & 21 & 64 \\
\hline DM & 10 & 50 & 50 & 54 \\
\hline PM & 13 & 31 & 69 & 54 \\
\hline NM & 10 & 70 & 30 & 55 \\
\hline Dystrophie & 10 & 70 & 30 & 47 \\
\hline
\end{tabular}

Im Folgenden sind die Ergebnisse der RT-PCR nach Parameter und Erkrankungsgruppe sortiert und in relativer Expression zur Endogenkontrolle GAPDH grafisch dargestellt (Abbildung 9).

Die mRNA-Expression des Chemokins CXCL10 zeigte sich in den Proben der IBMErkrankten und den der NM-Patienten im Vergleich zur Kontrollgruppe erhöht. Für die Proben der DM, PM und hereditären Muskeldystrophie ließ sich eine verminderte 
Expression im Vergleich zur Kontrollgruppe ermitteln. Statistisch signifikant ist der Vergleich von Kontrollgruppe zur IBM mit einem $p$-Wert von 0,007.

In allen Erkrankungsgruppen stellte sich eine erhöhte mRNA-Expression im Vergleich zur Kontrollgruppe in Bezug auf beide untersuchten GTPasen dar. Eine signifikante Hochregulation besteht bei der Expression des GBP5 in der IBM-Kohorte ( $p$-Wert = 0,0006). Bei Betrachtung der mRNA-Expression von NLRC5 zeigte sich eine nahezu ausnahmslos erhöhte Expression in allen Erkrankungen im Vergleich zur Kontrollgruppe. Allein die Biopsiegruppe der NM präsentiert mit einem Mittelwert von 0,000398 der relativen Expression im Vergleich zu GAPDH eine annähernd gleiche Expression wie die Kontrollgruppe mit einem Mittelwert von 0,000444. Die NLRC5-Expression der IBM-Gruppe ist im Vergleich zur Kontrollgruppe mit einem p-Wert von 0,0006 signifikant vermehrt.

Die Expression von NLRP3 zeigte sich in der IBM, der PM und der NM erhöht, in der DM und hereditären Muskeldystrophie jedoch im Vergleich zur Kontrollgruppe vermindert. Dennoch konnte auch im Vergleich von Kontrolle und IBM-Proben konnte mit einem P-Wert von 0,08 keine Signifikanz nachgewiesen werden . 


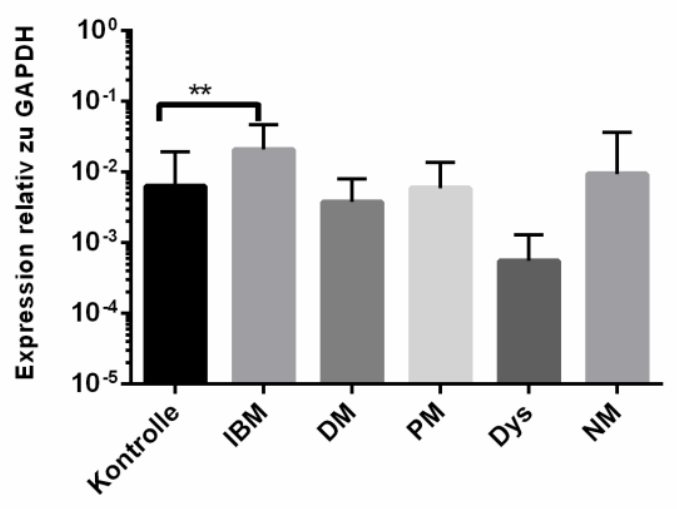

CXCL10

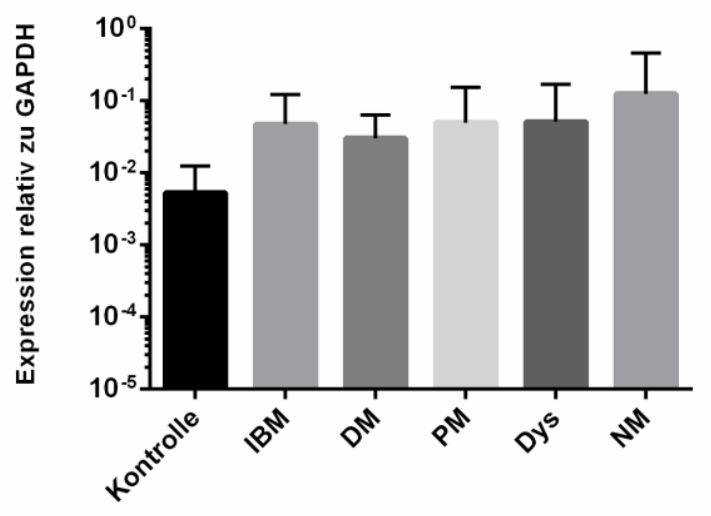

GBP1

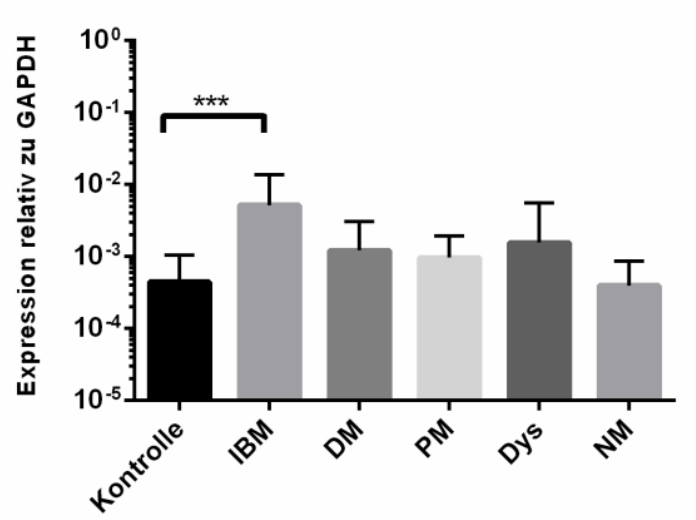

NLRC5

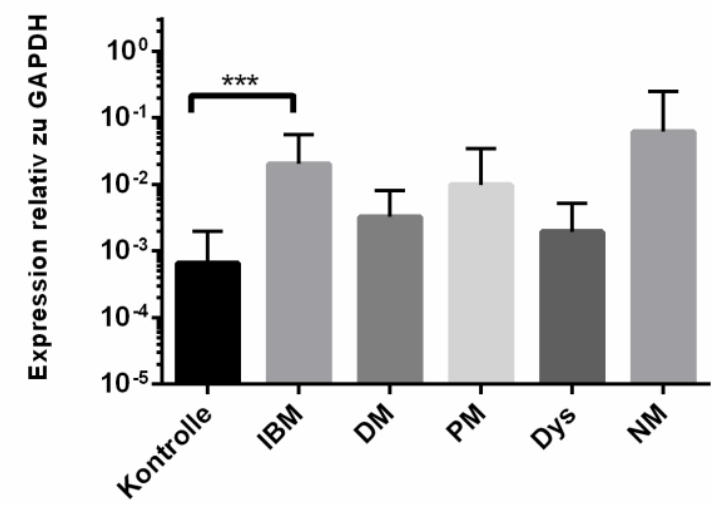

GBP5

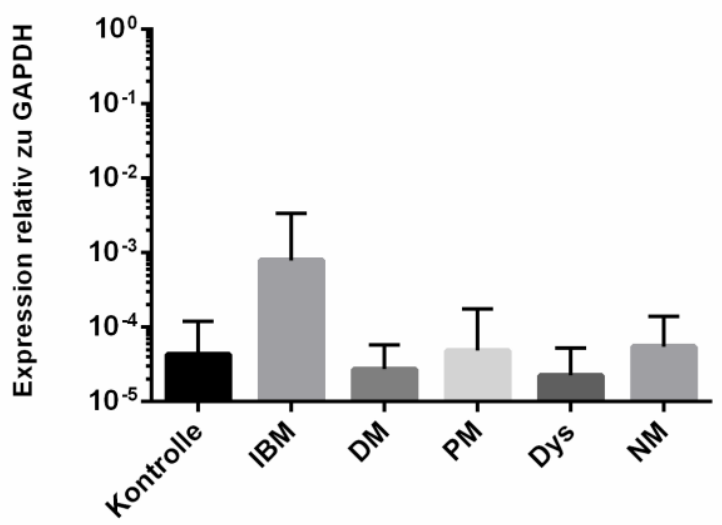

NLRP3

Abbildung 9) mRNA- Expression der Parameter relativ zur Endogenkontrolle GAPDH für alle Erkrankungsgruppen

Um eine bessere Übersicht der Genregulation der einzelnen Erkrankungsgruppen zu erreichen, werden die ermittelten Daten nach Erkrankung sortiert ein weiteres Mal dargestellt (Abbildung 10). 
Der errechnete Faktor der Regulation der Zielgene zwischen Stimulation und Kontrolle bzw. IBM-Patienten und Kontrollgruppe zeigt sich in allen Fällen positiv. Die Regulation von CXCL10, GBP1 und GBP5 ist im in vitro Experiment deutlich größer als in den Patientenproben. NLRC5 und NLRP3 zeigen eine annähernd gleiche Regulation in dem Zellkulturmodell und im Patientenvergleich (Abbildung 11).
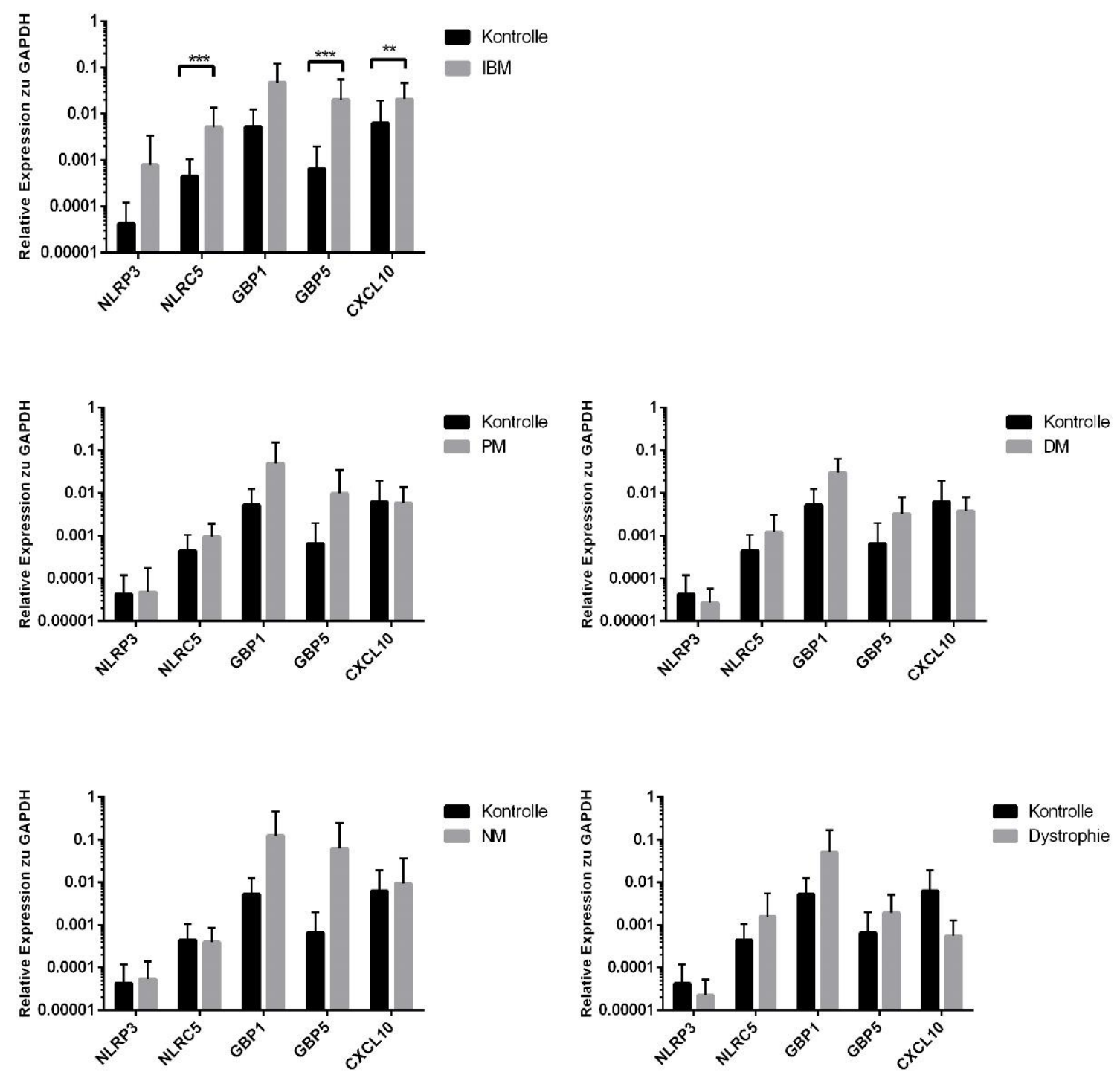

Abbildung 10) Relative mRNA-Expression der untersuchten Parameter zur Endogenkontrolle GAPDH als Übersicht der Erkrankungsgruppen im direkten Vergleich zur Kontrollgruppe 


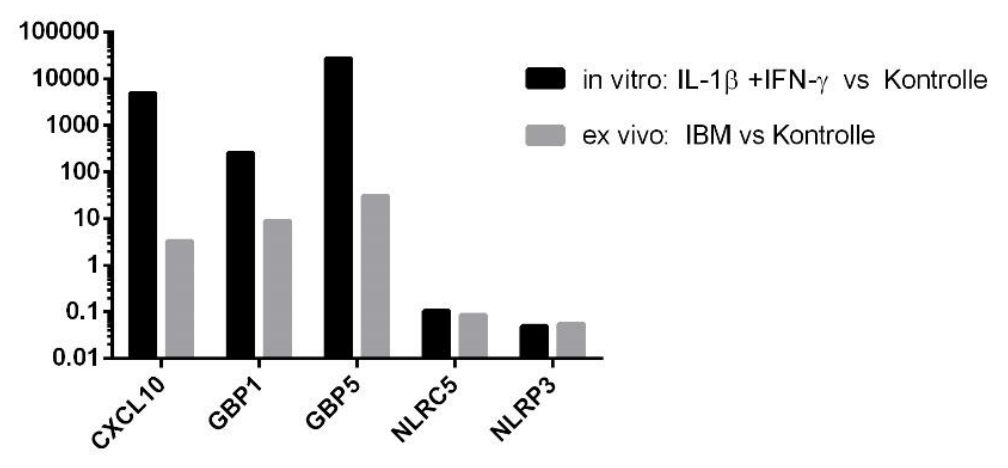

Abbildung 11) Errechneter Regulationsfaktor der einzelnen Zielgene von Stimulation zur Kontrolle bzw. IBM-Patienten zur Patienten-Kontrolle 


\section{Diskussion}

Die Einschlusskörpermyositis ist eine chronisch progrediente, erworbene Myositis des höheren Lebensalters. Die genaue Pathogenese der IBM ist zu dem aktuellen Zeitpunkt nicht geklärt, degenerative und entzündliche Mechanismen scheinen jedoch beidermaßen an der Erkrankungsentstehung und -unterhaltung mitzuwirken. Verbindungen zwischen diesen beiden Pfaden weisen auf ein gegenseitiges Wechselspiel der Mechanismen hin. So bilden eine erhöhte iNOS und dysfunktionale Autophagiesysteme Verbindungspunkte zwischen Entzündung und Degeneration (Schmidt und Schmidt 2017). Des Weiteren bedingt eine hohe Entzündungsaktivität in Form von IL-1 $\beta$ eine hohe Rate an Proteinakkumulation (Keller et al. 2017).

Das NLRP3-Inflammasom ist ein wichtiger Katalysator der Freisetzung von IL-1 $\beta$ in der angeborenen Immunantwort. Viele Überschneidungen zwischen bisher bekannten Aktivatoren dieses Inflammasoms und Bestandteilen der Proteinaggregationen der IBM legen die Vermutung nahe, dass sich in dem NLRP3-Inflammasom eine weitere Verbindung zwischen Entzündungsmechanismen und Degeneration verbirgt.

In vorhergehenden Arbeiten konnte bereits nachgewiesen werden, dass sich Muskelzellen als immunologisch aktiver Bestandteil in die Pathogenese der IBM einbringen. Eine Hochregulation und Expression von MHC-I und ICOS-Liganden, wie sie typischerweise bei professionellen Antigen-präsentierenden Zellen beobachtet wird, befeuert eine klonale CD8 ${ }^{+}$ T-Zell-Expansion, Zellinvasion und Nekrosen (de Paepe und Zschüntzsch 2015).

Sowohl in dem gut etablierten in vitro-Modell für chronische Muskelentzündung wie bei der IBM (Schmidt et al. 2008) als auch in Patientenbiopsien konnte in dieser Arbeit eine Hochregulation von Chemokinen, den GBPs und des NLRP3 dargestellt werden.

Immunzytochemische Anfärbungen und Western Blots zeigten eine Hochregulation von NLRP3 nach 24-stündiger Inkubation der Myotuben mit IL-1 $\beta$ und IFN- $\gamma$ auf Proteinebene. Nachdem im Vorfeld einige NLRP3-spezifische Antikörper wegen unzuverlässiger Anfärbung von Banden im Western Blot ausgeschlossen werden mussten, zeigte der zuletzt verwendete polyklonale Antikörper eine reproduzierbare Anfärbung der Proteinbande auf vorhergesagter Bandenhöhe ohne starke unspezifische Anfärbung anderer Proteinbanden. In der Auswertung der immunzytochemischen Färbung wurde ein unspezifisches Signal vorab durch einen visuellen festgelegten Schwellenwert reduziert. Ein übermäßig starkes Signal wurde als unspezifisch angesehen, sobald es von Zellen 
gezeigt wurde, welche in der Stimulationskontrolle mittels MHC-I keine Reaktion auf die zugegebenen Zytokine zeigten.

Es konnte in beiden Verfahren eine Hochregulation des NLRP3-Proteins nachgewiesen werden und diese war im Western Blot signifikant. Die Experimente wurden mit Myotuben verschiedener Probanden durchgeführt und reproduziert. Alle Experimente zeigten eine Hochregulation, jedoch in unterschiedlichem Ausmaß bei divers ausgeprägtem Grundniveau des Inflammasoms. Diese hohe biologische Varianz begründet einen großen Standardfehler und somit eine fehlende Signifikanz der Ergebnisse. Auch das Zeitverlaufsexperiment mit Stimulationsdauern von 48 und 72 Stunden erbrachte dieses Ergebnis. Über den Zeitverlauf konnte zum einen ein leicht steigendes Grundniveau der NLRP3-Expression in den Kontrollproben, zum anderen auch ein kurzfristiges Ansteigen der Proteinexpression bis zum Zeitpunkt von 48 Stunden und ein leichter Abfall im Intervall von 48- bis 72 Stunden beobachtet werden. Zu beachten ist bei diesen Daten, dass in der Auswertung für 24- und 48 Stunden jeweils sechs Experimente einbezogen werden konnten, für den Zeitpunkt von 72 Stunden jedoch nur vier Experimente verwertbar waren. Bis zum Beenden des Stimulationszeitraumes war in zwei Fällen eine erhöhte Sterberate der Zellen dafür verantwortlich, dass diese Experimente nicht weiter gefärbt und ausgewertet werden konnten.

Diese in vitro Experimente wurden auch auf eine Hochregulation auf mRNA-Ebene hin untersucht. Hier konnte nach einer Stimulationsdauer von 24 Stunden bereits eine signifikante Hochregulation des Zielgens NLRP3 dargestellt werden.

Zusätzlich untersuchte Zielgene der Gruppe der Chemokine zeigten sich nach 24-stündiger Stimulationsdauer ebenfalls signifikant erhöht. Größtenteils wird deren Freisetzung durch inflammatorische Zytokine induziert, die auch im entzündlichen Milieu der IBM eine tragende Rolle spielen (de Paepe et al. 2009). Auffällig ist jedoch auch die migrationsfördernde Rolle auf T-Zellen, die einige dieser deutlich überexprimierten Chemokine besitzen. So scheint eine weitere Verstärkung der T-Zell-Aktivierung und Invasion durch die Muskelzellen selbst stattzufinden. Neben einer verstärkten Migration und Invasion von zytotoxischen T-Zellen durch Chemokine ist die Hochregulation von MHC-I als eine essentielle Grundlage für die Aktivierung dieser T-Zellen im histologischen Bild der IBM nachweisbar (Figarella-Branger et al. 2003). Das im Experiment signifikant hochregulierte NLRC5 könnte einen weiteren Baustein in der Inflammationskaskade der Erkrankung darstellen. Die positiv regulatorische Wirkung auf die MHC-I Expression ist konkordant zu der bekannten, starken Hochregulation des MHC-I im histologischen Bild der PM und hat einen synergistischen Effekt zu der Hochregulation von CXCL10, CXCL11 und CCL20 auf die T-Zellaktivierung (Rayavarapu et al. 2013). 
In Bezug auf die Expression der GBPs ist ebenfalls eine signifikante Hochregulation beider Proteine gezeigt worden. Beide sind unter anderem durch Interferone induziert und wurden bereits in weiteren systemisch-inflammatorischen Erkrankungen wie der rheumatoiden Arthritis nachgewiesen (Naschberger et al. 2017). Somit liegt der Schluss nahe, dass sie in der Kaskade der IBM-Entstehung eine Rolle spielen können. Vor allem das GBP5, welches direkt in die Wirkung des NLRP3 eingreift und verstärkt, kann einen Bestandteil des IL-1ßFreisetzungspfades darstellen.

Generell konnte für alle Parameter eine zwar unterschiedlich stark ausgeprägte, aber jedoch in jedem Fall vorhandene Expression in der Kontrollgruppe nachgewiesen werden. In der Literatur wird bereits eine konstitutive muskuläre Expression einiger Zytokine wie IL6, Chemokine wie CCL3 und CCL5 und in geringem Maße von MHC-I beschrieben (Figarella-Branger et al. 2003). Die Ergebnisse der in vitro Experimente legen nahe, dass die untersuchten Zielgene ebenfalls $\mathrm{zu}$ den konstitutiv exprimierten und durch inflammatorische Zytokine weiter induzierbaren Proteinen gehören.

Die Regulation einiger der untersuchten Zielgene wurde im Verlauf in Patientenproben der IIMs, hereditären Muskeldystrophien und Kontrollpatienten untersucht. In der epidemiologischen Betrachtung der untersuchten Muskelproben zeigte sich für die IBM und die PM eine zur Literatur passende Verteilung der Geschlechter und des Biopsiealters. In den Gruppierungen der DM und der NM differierte das Geschlechterverhältnis der untersuchten Proben zu den Literaturangaben. Das Biopsiealter der DM-Patienten korrelierte mit dem Erkrankungsgipfel der adulten DM, im Fall der NM-Patienten zeigte sich eine große Differenz im Biopsiezeitpunkt der weiblichen und der männlichen Patienten. Die Gruppe der hereditären Muskeldystrophien enthält ein gemischtes Spektrum an Erkrankungen und Vererbungsformen, weshalb in diesem Rahmen keine allgemeingültige Aussage zum Geschlechterverhältnis und zum Manifestationsalter getroffen werden kann.

In Betrachtung der Regulation der CXCL10-mRNA zeigte sich eine Hochregulation in den Proben der IBM und der NM. Im Vergleich zur Kontrollgruppe wurde eine verminderte Expression in den Proben der DM, PM und Dystrophie nachgewiesen. In Übereinstimmung mit bisherigen Veröffentlichungen ist das Transkript in den Proben der IBM hochreguliert (de Paepe et al. 2008). Schlüssig ist es auch, dass eine deutliche Hochregulation in den Erkrankungen mit CD8 ${ }^{+}$-T-Zell- und Makrophagendominanz erreicht wurde. Die Dystrophien ohne primär entzündliches Infiltrat und die DM mit prädominanter B-Zell-Reaktion zeigten eine Herunterregulation im Vergleich zur Kontrolle. Auch in der Literatur wurde zumindest für die DM ein zur IBM und PM differierendes Chemokinmuster mit Überexpression von B-Zellstimulierenden Zytokinen beschrieben (de Paepe et al. 2008; de Paepe et al. 
2009). Zwar besticht die Histopathologie der PM auch durch eine CD8+-T-Zelldominanz, zeigte jedoch eine minimale Reduktion der CXCL10-Expression. Ein Erklärungsansatz für diese Auffälligkeit ist, dass nachgewiesenes CXCL10 in der PM bisher nur in den infiltrativen Makrophagen und T-Zellen lokalisiert wurde. Es wurden zwar erhöhte Proteinwerte des CXCL10 in Muskelbiopsien nachgewiesen, ein erhöhtes Transkript wurde in den Muskelzellen selbst bisher nicht bestimmt. Dieses konnte jedoch für die IBM nachgewiesen werden (de Paepe et al. 2008; de Paepe et al. 2009). Das eigene Experiment mit Myotuben zeigte ebenfalls eine CXCL10-Transkripthochregulation, weshalb davon ausgegangen werden muss, dass Muskelfasern selbst in der IBM CXCL10 heraufregulieren können.

Im Vergleich dazu zeigte sich ein ausnahmslos erhöhtes GBP1- und GBP5-Transkript in allen Erkrankungsgruppen. Erklärbar ist eine Erhöhung der Expression der GBP-mRNA in den IIMs, da eine generelle Induktion durch IFN-y bekannt ist (Shenoy et al. 2012). In Bezug auf eine Stimulation des GBP1 war diese bisher bei inflammatorischer Endothelaktivierung am stärksten nachweisbar. Diese Erkenntnis ließ die Vermutung zu, dass das GBP1 Transkript in der DM am stärksten reguliert wäre. Warum dieses jedoch nicht der Fall war, ist zu diesem Zeitpunkt unklar. Die deutliche Hochregulation des GBP1 in der Dystrophiegruppe lässt sich möglicherweise auf sekundäre Entzündungsmechanismen in den Muskeln zurückführen, welche einen weiteren Erkrankungsprozess befeuern.

Die GBP5 Expression zeigte sich zwar in allen untersuchten Erkrankungsgruppen erhöht, sollte aber aufgrund der synergistischen Wirkweise in Zusammenschau mit den Expressionswerten des NLRP3 betrachtet werden. Diese erwiesen sich in der IBM, der PM und der NM erhöht, in der DM und Dystrophie vermindert. In Korrelation dazu zeigte sich auch in der Analyse des GBP5 in der IBM, der PM und der NM eine stärkere Hochregulation als in den anderen beiden Gruppen. Entgegen vorheriger Veröffentlichungen konnte keine gesteigerte Expression des NLRP3 in DM-Patienten nachgewiesen werden (Yin et al. 2016). Da erhöhte IL-1 $\beta$ Spiegel in allen IIMs eine wichtige Rolle spielen, wäre eine Steigerung der mRNA-Expression in allen Erkrankungsgruppen erwartet worden (De Paepe et al. 2009).

Für die PM gibt es Hinweise, dass ein hoher Spiegel von Cathepsin B mit einer starken Krankheitsaktivität korreliert (Yin et al. 2016). Da Cathepsin B als einer der drei aktuell diskutierten Aktivierungspfade des NLRP3 gilt, ist eine Hochregulation des NLRP3 und des unterstützenden GBP5 in den Proben der PM-Patienten zu erklären.

Im Rahmen der Nekrose von Muskelzellen in der NM werden lokal vermehrt DAMPs freigesetzt, welche bereits erwiesenermaßen Aktivatoren des Inflammasoms und im speziellen des NLRP3 Inflammasoms sind. So ist auch die Überexpression des NLRP3 in der NMGruppe auf einen Pathomechanismus der Erkrankung zurückzuführen. 
Für die im Ausmaß am stärksten ausfallende Hochregulation in der IBM lassen sich mehrere Erklärungen finden. Zum einen gelten Bestandteile der ubiquitär auftretenden Proteinaggregate als Aktivatoren des NLRP3, zum anderen konnten in der IBM zwar durch Zytokine hochregulierte, dennoch dysfunktionale Autophagiesysteme beobachtet werden (Askanas et al. 2015; Schmidt et al. 2017). Durch diesen fehlenden physiologischen Suppressor des Inflammasoms besteht demnach ein erhöhtes Aufkommen an ROS, welches einen Bestandteil eines der aktuell diskutierten Aktivierungsweges des NLRP3 darstellt (Robbins et al. 2014).

In Betrachtung der Expressionswerte in der Dystrophie zeigte sich die GBP5-mRNA zwar leicht erhöht zur Kontrolle, wies aber die geringste Regulation aller Erkrankungsgruppen auf. Die NLRP3-Expression wurde sogar herunterreguliert. Diese Ergebnisse entsprechen der Pathogenese der Dystrophien, deren Pathologie aus Proteinmutation und -verlust mit einhergehendem Wechsel aus Degeneration und Regeneration und fibrotischem Umbau besteht. Erhöhte GBP1- und GBP5-Messwerte können Ausdruck des generellen Zellstresses sein. Untersuchungen am Mausmodell der Duchenne Muskeldystrophie ergaben zusätzlich eine aktive Suppression von NLRP3 durch ein vom Fettgewebe sezerniertes Hormon (Boursereau et al. 2018). Diese Mechanismen könnten bei hier verwendeten Proben, welche zwar keine Duchenneproben enthielten, jedoch auch dem Umbau von Muskelzellen in Binde- und Fettgewebe unterliegen, ebenfalls zum Tragen kommen und diese leichte Reduktion der NLRP3-Expression im Vergleich zum konstitutiven Niveau bewirken.

Eine erhöhte mRNA-Expression von NLRC5 zeigten die Proben der IBM, Dystrophien, DM und PM in abnehmender Reihenfolge, wohingegen die Gruppe der NM eine minimal verminderte Expression im Vergleich zur Kontrolle aufwies. In vitro-Studien belegten im Vorfeld dieser Arbeit eine deutliche Induzierbarkeit des NLRC5 durch IFN-y und die aktivierende Funktion des NLRC5 auf MHC-I kodierende Gene. Knockoutversuche bestätigten weiterhin die IFN- $\gamma$-induzierte MHC-I-Hochregulation vorwiegend durch NLRC5 (Meissner et al. 2010).

Dementsprechend zeigten vor allem die Erkrankungen der IIMs mit ubiquitär erhöhtem MHC-I-Komplex ein zur Kontrolle erhöhtes NLRC5. Die NM weist in der Histopathologie eine nur gering gesteigerte Expression von MHC-I an nekrotischen Faserarealen und eine Prädominanz von Makrophagen auf. Eine Hochregulation des MHC-I-Komplexes und der spezifischen Immunantwort ist in der Pathogenese also zweitrangig und auch im Vergleich zur gesunden Kontrollgruppe vernachlässigbarer. Der gesunde Kontrollmuskel zeigte eine konstitutive Expression des NLRC5, um durch diesen Pfad eine physiologische Schnittstelle zwischen angeborener und adaptiver Immunantwort zu bilden und auf virale und bakterielle 
Angriffe reagieren zu können. Dem entsprechend zeigte sich die mRNA-Expression des NLRC5 in der NM gering unter dem konstitutiven Niveau.

In den Untersuchungen wurde der Therapiestatus der Patienten und der aktuelle Entzündungsgrad zum Zeitpunkt der Biopsie nicht mitbetrachtet. So können interindividuelle Schwankungen innerhalb einer Gruppe und Diskrepanzen zu vorhergehenden Veröffentlichungen erklärbar sein. Vor allem in Bezug auf die Bestimmung der NLRP3-Transkripte in der DM und PM differieren diese Ergebnisse zu vorhergehenden Veröffentlichungen. In einigen Studien scheinen anhand der Auswahlkriterien mit deutlich erhöhter Serum-CK und -LDH, einem großen Anteil an Patienten mit EMG-Veränderungen und einer ausgeprägten Muskelschwäche in allen Fällen, nur Patienten mit hoher Entzündungsaktivität ausgewählt worden zu sein (Yin et al. 2016). Diese Selektion wurde in dieser Dissertation nicht vorgenommen.

Für die RNA-Extraktion wurde das gesamte Biopsiematerial verwendet. Neben Muskelzellen waren somit auch Binde- und Fettgewebe, Endothel und infiltrative Zellen in dem Biopsat enthalten und wurden für die RNA-Extraktion im Gesamten genutzt. Im Rahmen dieser Arbeit lässt sich also nur eine Aussage über die quantitative Regulation, jedoch nicht die Distribution und die Unterschiede in der Synthese beziehungsweise der Syntheseorte innerhalb der verschiedenen Erkrankungsgruppen treffen. Der Vergleich zwischen in vitro Experiment und Regulation von Kontrollgruppe zur IBM lässt Schlüsse darauf zu, dass die Myotuben ohne Einfluss von infiltrativen Immunzellen oder Fibroblasten und Endothel unter den inflammatorischen Bedingungen der IBM alle untersuchten Zielgene regulieren. Errechnete Regulationsfaktoren zeigten, dass das in vitro Modell in Bezug auf die Hochregulation des Inflammasoms und des NLRC5 ein annähernd gleiches Ausmaß zeigte. Die Überexpression des Chemokins und der GBPs im Zellkulturmodell ist auf eine gezielte Stimulation durch die Zytokine, fehlende negative Feedbackschleifen und mögliche Therapieeffekte zu erklären, welche in vivo parallel zu der positiven Stimulation ablaufen und eine Regulation beeinflussen.

In Zusammenschau der Ergebnisse ließ sich für die einzelnen Erkrankungsgruppen ein Bild über die Hochregulation von inflammatorisch wirksamen Proteinen und vor allem auf zytotoxische T-Zellen wirksame Chemokine sowie Aussagen über synergistisch wirksame Effekte auf die MHC-I Expression machen.

So zeigten die Ergebnisse der IBM eine signifikante Überexpression von CD8+-T-Zell- anziehendem CXCL10 und dem MHC-I induzierenden NLRC5. Über das deutlich gesteigerte NLRP3-Transkript sowie die Hochregulation des unterstützenden GBP5 lassen sich die hohen IL-1 $\beta$ Spiegel, die in dieser Erkrankung beobachtet werden, erklären. Generell höhere 
Expressionswerte aller untersuchten Zielgene lassen sich auf die ubiquitär und deutlich gesteigerten Zytokinlevel von IL-1 $\beta$ und IFN-ү zurückführen. Die Zytokinverteilungsmuster differieren in der Polymyositis und Dermatomyositis dazu deutlich. In der PM konnte bisher eine deutliche Elevation der Zytokine hauptsächlich in der Umgebung von stark geschädigtem Muskelgewebe nachgewiesen werden, in der DM dagegen nicht in den Muskelfasern selber, sondern in umgebendem Gewebe und Kapillaren (Schmidt et al. 2008).

Ein einander größtenteils ähnliches Expressionsmuster zeigten die PM, DM und die NM. Bei allen Entitäten ließ sich ein deutlich hochreguliertes GBP1 als Zeichen der systemischen Inflammation beobachten. Leichte Unterschiede in der Auswirkung auf CXCL10 lassen sich durch die Pathogenese erklären. Da in der DM ein Hauptteil der Immunantwort über den humoralen Pfad erfolgt und primär B-Zellen und CD4+-T-Zellen aktiviert, ist hier ein im Vergleich geringerer Anstieg als in den CD8 ${ }^{+}$-T-Zell- und makrophagendominierten PM und NM zu erwarten. Diese deutlich diversen zellulären Reaktionen erklären auch die Hochregulation des intrazellulären Inflammasoms und des supportiven GBP5 in der PM und NM wohingegen die DM eine solche Expression nicht aufwies. Die NLRC5-Regulation korreliert bei den drei Erkrankungen mit der Ausprägung der MHC-I-Expression.

Die Proben der Dystrophie wiesen eine erhöhte Expression von GBP1, GBP5 und NLRC5 auf, was auf eine sekundäre krankheitsfördernde Entzündung schließen lässt. Eine spezifische Aktivierung und Hochregulation des Inflammasoms ließ sich jedoch nicht nachweisen. Zum einen könnte das Hormon Adiponektin als Suppressor des NLRP3 diesen Effekt bewirken, zum anderen gehen in der Muskeldystrophie De- und Regeneration mit einem mehr oder minder kontrollierten Umbau in Binde- und Fettgewebe einher, wodurch kaum Nekrose eintritt und weniger DAMPs freigesetzt werden.

Im Rahmen dieser Arbeit ließ sich eine deutliche Hochregulation des NLRP3-Inflammasoms im in vitro Experiment auf transkriptionaler und translationaler Ebene nachweisen. Auch die weitergehende Untersuchung von IBM-Muskelbiopsien erbrachte eine deutlich vermehrte Expression des NLRP3 und unterstützender Proteinkomplexe auf mRNA-Ebene. Auch in den idiopathisch inflammatorischen Myositiden PM und NM konnte dieses Ergebnis bestätigt werden.

Ob diese Heraufregulation primär auf inflammatorischen Prozessen basiert oder sekundäre Folge von endogenem Zellstress durch Proteinakkumulation ist, vermag diese Arbeit nicht beantworten. Jedoch konnte aufgezeigt werden, dass das NLRP3-Inflammasom in der IBM 
auf Genebene und auch als Genprodukt signifikant hochreguliert wird. Als wichtiger Bestandteil der inflammatorischen Seite der Pathogenese kann inm gewiss eine krankheitsfördernde und -unterhaltende Rolle durch die IL-1 $\beta$ Freisetzung zugesprochen werden.

Eine Limitation dieser Arbeit ist in der fehlenden Distributionsanalyse des NLRP3 innerhalb der Muskelbiopsien der verschiedenen Erkrankungen zu sehen. Auch sollten Nachweise von dem direkten Kaskadenendprodukt IL-1 $\beta$ in direkte Korrelation zur NLRP3- und GBP5Regulation erbracht werden, um nicht nur eine reine Regulation, sondern auch eine translationale Auswirkung beurteilen zu können. Des Weiteren ist eine direkte Korrelation von NLRP3-Regulation und dem Ausmaß von Proteinaggregation zu untersuchen, um eine direkte Verbindung der beiden Pfade herzustellen.

\subsection{Schlussfolgerung}

In Bezug auf die Ausgangsfrage eines weiteren Verbindungsweges zwischen Degeneration und Inflammation lässt sich in Anbetracht dieser Arbeit das Inflammasom als ein weiterer Faktor ableiten. Die durchgeführten Untersuchungen zeigen sowohl im Zellmodell, als auch im Patientenmaterial eine erhöhte Expression des NLRP3-Inflammasoms. Auch die Hochregulation der weiteren Chemokine, GBPs und NLRC5 lassen sich in Einklang mit den bekannten histologischen Veränderungen in der IBM und die bisher diskutierte Pathogenese bringen (Abbildung 12). Es sind nachfolgende Untersuchungen notwendig um die genaue Rolle des NLRP3 in der Pathogenese der IBM zu definieren. Neben einer Analyse der Regulation des Endproduktes IL-1 $\beta$ in Korrelation mit dem NLRP3 ist eine weitere Korrelation von NLRP3 zu Proteinaggregationen, sowie eine histologische Darstellung des Verteilungsmusters des NLRP3 notwendig. Zusätzlich wäre ein Knock-out Versuch des NLRP3 eine Möglichkeit direkte Auswirkungen des NLRP3 auf den Inflammationsstatus der Zellen, die Regulation des IL-1 $\beta$ und eine Ansammlung von Proteinaggregaten direkt ausgehend von der Inflammation durch NLRP3 zu quantifizieren. Nachfolgend lässt sich daraus möglicherweise der Nutzen einer targeted therapy im Sinne einer NLRP3-Blockade im Mausmodell der IBM und als Therapieoption in vivo ableiten. 


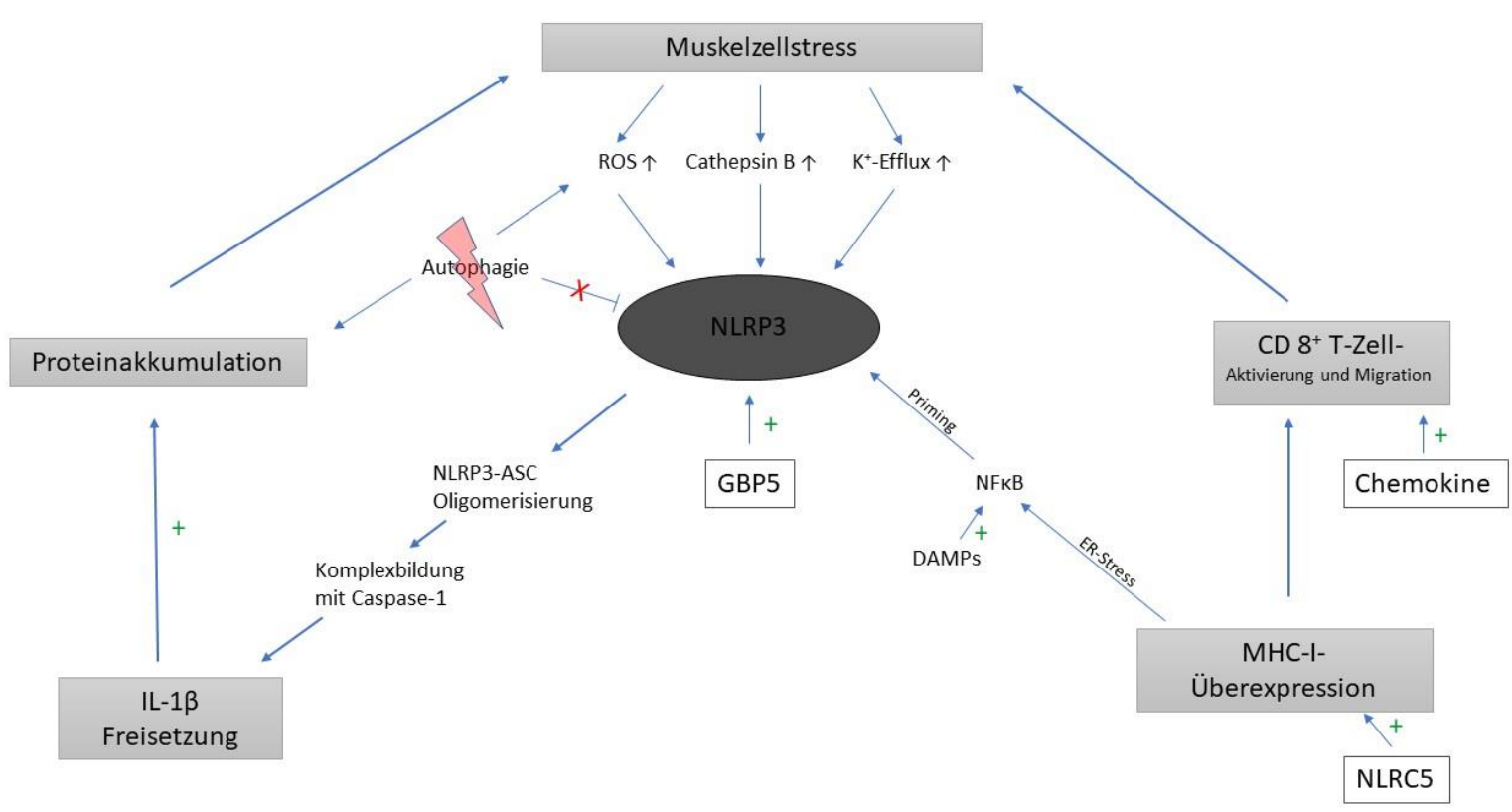

Abbildung 12) Eigene Darstellung der vermutlichen NLRP3- Rolle im entzündeten Muskel: Eckpfeiler der IBM Pathogenese sind ein proinflammatorisches Milieu mit IL-1 $\beta$, eine histologisch nachweisbare MHC-I-Überexpression auf den Muskelzellen, T-Zellmigration und Proteinakkumulation in den Myotuben. Bekanntermaßen führt ein erhöhtes IL-1 $\beta$ zu verstärkter APP-Akkumulation. Durch die MHC-I-Überexpression kommt es unter Chemokineinfluss zur T-Zell-Aktivierung und -Migration. Beides sind Ausgangspunkte für vermehrten Muskelzellstress. Hierunter kommt es in den Zellen zur Freisetzung der NLRP3-Aktivatoren (ROS, Cathepsin B und Kalium-Efflux). Dysfunktionale Autophagieprozesse befördern zum einen die Proteinakkumulation in den Myotuben, zum anderen ist der Abbau von ROS in der Zelle vermindert. Eine hemmende Wirkung der Autophagie auf das NLRP3 selbst entfällt ebenfalls. Das Priming und die Induktion des NLRP3 erfolgt parallel über den NFKB-Pfad. Die Aktivierungswege des NLRP3 einschließlich Oligomerisierung und Komplexbildung von NLRP3 mit ASC und Pro-Caspase 1 führen wiederum zu verstärkter IL-1 $\beta$-Freisetzung. Auch die supportive Wirkung des GBP5 und die positiv-regulatorische Wirkung des NLRC5 verstärken diese Prozesse. 


\section{Zusammenfassung}

Die Einschlusskörpermyositis (inclusion body myositis, IBM) ist eine inflammatorische Myopathie, die üblicherweise nach dem 50. Lebensjahr beginnt und durch weiter steigende Inzidenz und deutlichere Diagnosekriterien fortwährend an Beachtung gewinnt. Durch ein Zusammenspiel an Inflammation und Degeneration stellt sie eine Ausnahme in der Gruppe der Myositiden dar. Zwar konnten bereits einige Interaktionen zwischen Entzündung und Proteinakkumulation entschlüsselt werden, der genaue Pathomechanismus der Erkrankung bleibt aber bisher ungeklärt. In vorhergehenden Studien stellte sich im Vergleich zur Polymyositis und Nekrotisierenden Myopathie vor allem in der IBM die herausragende Rolle der Zytokine IL-1 $\beta$ und IFN- $\gamma$ in der Erkrankungsentstehung und unterhaltung heraus. Systemische aseptisch, inflammatorische Erkrankungen wie das cryopyrin-associated-periodic-syndrome (CAPS) gehen nachweislich mit hohen IL-1 $\beta$ Spiegeln einher und beruhen auf einem Gain-of-function-Defekt des NLRP3Inflammasoms. Da intrazelluläre Proteinakkumulation und endogener Zellstress, welches in DAMP-Freisetzung resultiert, gleichsam als Aktivatoren des NLRP3 nachgewiesen wurden und in der Histopathologie der IBM auftreten, liegt der Schluss nahe das NLRP3Inflammasom als weitere Verbindung zwischen Inflammation und Degeneration zu betrachten. Immunzytochemische und molekularbiologische Nachweisverfahren konnten in dieser Arbeit eine Hochregulation des NLRP3-Inflammasoms in einem Zellkulturmodell der IBM bestätigen. Auch in Patientenbiopsien konnte eine deutliche Hochregulation des Inflammasoms gezeigt werden. Zusätzlich untersuchte Zielgene, welche synergistisch auf das Inflammasom, die T-Zell-Migration und die MHC-I-Expression wirken, zeigten sich ebenfalls hochreguliert. Vergleichende Nachweise der Genregulation in Patientenbiopsien von Polymyositis-, Dermatomyositis-, Nekrotisierender Myopathie- und Dystrophiepatienten sowie einer muskelgesunden Kontrollgruppe zeigten eine NLRP3-Hochregulation bei der Polymyositis und Nekrotisierenden Myopathie. Entgegen einzelner Veröffentlichungen konnte eine Hochregulation in dem Patientenkollektiv der Dermatomyositis nicht bestätigt werden. Eine gesteigerte mRNA-Expression des Chemokins CXCL10 konnte nur in der IBM und der NM-Kohorte belegt werden. Weiterhin zeigten sich die GTPasen GBP1 und GBP5 in allen Erkrankungsgruppen im Vergleich zu der Kontrolle erhöht. Das MHC-I-induzierende NLRC5 wies in der IBM-, der Dermatomyositis-, der Polymyositis- und der Dystrophiegruppe eine gesteigerte relative mRNA-Expression auf. In Zusammenschau der Ergebnisse zeigt sich eine signifikante Hochregulation der NLRP3-RNA und des NLRP3Genprodukts sowohl in vitro als auch in vivo. Aufgrund der Besonderheiten der Pathogenese und der im Vergleich weitaus deutlicheren Hochregulation des NLRP3 bei der 
IBM ist das Inflammasom als weiterer Baustein der Inflammationskaskade in der Pathogenese und Krankheitsunterhaltung anzusehen. Ob die Regulation jedoch auch eine direkte Auswirkung auf degenerative Prozesse und das Ausmaß der Proteinakkumulation hat, bleibt noch nachzuweisen. 


\section{Literaturverzeichnis}

Askanas V, Engel WK, Nogalska A (2015): sporadic inclusion-body myositis: A degenerative muscle disease associated with aging, impaired muscle protein homeostasis and abnormal mitophagy. Biochim Biophys Acta BBA - Mol Basis Dis 1852, 633643

Benetti E, Chiazza F, Patel NSA, Collino M (2013): the NLRP3 Inflammasome as a novel player of the intercellular crosstalk in metabolic disorders. Mediators Inflamm 2013, 678627

Benveniste O, Stenzel W, Hilton-Jones D, Sandri M, Boyer O, van Engelen BGM (2015): amyloid deposits and inflammatory infiltrates in sporadic inclusion body myositis: the inflammatory egg comes before the degenerative chicken. Acta Neuropathol (Berl) $\underline{129}, 611-624$

Boursereau R, Abou-Samra M, Lecompte S, Noel L, Brichard SM (2018): downregulation of the NLRP3 inflammasome by adiponectin rescues Duchenne muscular dystrophy. BMC Biol $\underline{16}, 33$

Breithaupt M, Schmidt J (2014): treatment strategies for inclusion body myositis. Expert Opin Orphan Drugs $\underline{2}, 1255-1265$

Ceribelli A, de Santis M, Isailovic N, Gershwin ME, Selmi C (2017): the immune response and the pathogenesis of idiopathic inflammatory myositis: a critical review. Clin Rev Allergy Immunol $\underline{52}, 58-70$

Chiang S, Ubogu EE (2013): the role of chemokines in Guillain-Barré syndrome. Muscle Nerve $\underline{48}, 320-330$

Davis BK, Wen H, Ting JPY (2011): the inflammasome NLRs in immunity, inflammation, and associated diseases. Annu Rev Immunol $\underline{29}$, 707-735

de Paepe B, Zschüntzsch J (2015): scanning for therapeutic targets within the cytokine network of idiopathic inflammatory myopathies. Int J Mol Sci $\underline{16}, 18683-18713$

de Paepe B, Creus KK, de Bleecker JL (2008): chemokines in idiopathic inflammatory myopathies. Front Biosci J Virtual Libr 13, 2548-2577

de Paepe B, Creus KK, de Bleecker JL (2009): role of cytokines and chemokines in idiopathic inflammatory myopathies. Curr Opin Rheumatol 21, 610-616

Degrandi D, Konermann C, Beuter-Gunia C, Kresse A, Würthner J, Kurig S, Beer S, Pfeffer K (2007): extensive characterization of IFN-Induced GTPases mGBP1 to mGBP10 involved in host defense. J Immunol 179, 7729-7740

DGN (2015): Leitlinie Myositissyndrome (AWMF-Registernummer 030/054). S2k-Leitlinie der Gesellschaft für Neurologie, https://dgn.org/leitlinien/ll-69-II-myositissyndrome/, Zugriff am 01.09.2015

DGN (2016): Leitlinie Diagnostik von Myopathien (AWMF-Registernummer 030/115). S1Leitlinie der Gesellschaft für Neurologie, https://www.awmf.org/leitlinien/detail/ll/030-115.html; Zugriff am 06.08.2016 
Ding M, Huang T, Zhu R, Gu R, Shi D, Xiao J, Guo M, Li J, Hu J, Liao H (2018): immunological behavior analysis of muscle cells under IFN-y stimulation in vitro and in vivo. Anat Rec Hoboken NJ 2007 1551-1563

Farrell GC, Haczeyni F, Chitturi S (2018): pathogenesis of NASH: how metabolic complications of overnutrition favour lipotoxicity and pro-inflammatory fatty liver disease. Adv Exp Med Biol 1061, 19-44

Figarella-Branger D, Civatte M, Bartoli C, Pellissier JF (2003): cytokines, chemokines, and cell adhesion molecules in inflammatory myopathies. Muscle Nerve 28, 659-682

Halle A, Hornung V, Petzold GC, Stewart CR, Monks BG, Reinheckel T, Fitzgerald KA, Latz E, Moore KJ, Golenbock DT (2008): the NALP3 inflammasome is involved in the innate immune response to amyloid- $\beta$. Nat Immunol $\underline{9}, 857-865$

Hammon M, Herrmann M, Bleiziffer O, Pryymachuk G, Andreoli L, Munoz LE, Amann KU, Mondini M, Gariglio M, Airó P et al. (2011): role of guanylate binding protein-1 in vascular defects associated with chronic inflammatory diseases. J Cell Mol Med $\underline{15}, 1582-1592$

Hill CL, Zhang Y, Sigurgeirsson B, Pukkala E, Mellemkjaer L, Airio A, Evans SR, Felson DT (2001): frequency of specific cancer types in dermatomyositis and polymyositis: a population-based study. The Lancet $\underline{357}$, 96-100

Keller CW, Schmidt J, Lünemann JD (2017): immune and myodegenerative pathomechanisms in inclusion body myositis. Ann Clin Transl Neurol $\underline{4}, 422-445$

Kummer JA, Broekhuizen R, Everett H, Agostini L, Kuijk L, Martinon F, van Bruggen R, Tschopp J (2007): inflammasome components NALP 1 and 3 show distinct but separate expression profiles in human tissues suggesting a site-specific role in the inflammatory response. J Histochem Cytochem Off J Histochem Soc $\underline{55}$, 443-452

Lamkanfi M, Kanneganti TD (2010): Nlrp3: an immune sensor of cellular stress and infection. Int J Biochem Cell Biol 42, 792-795

Lin CC, Edelson BT (2017): new insights into the role of IL-1 $\beta$ in EAE and MS. J Immunol Baltim Md $1950 \underline{198}$, 4553-4560

Meissner TB, Li A, Biswas A, Lee KH, Liu YJ, Bayir E, lliopoulos D, van den Elsen PJ, Kobayashi KS (2010): NLR family member NLRC5 is a transcriptional regulator of MHC class I genes. Proc Natl Acad Sci U S A 107, 13794-13799

Menu P, Vince JE (2011): the NLRP3 inflammasome in health and disease: the good, the bad and the ugly. Clin Exp Immunol 166, 1-15

Meola G, Cardani R (2015): myotonic dystrophies: an update on clinical aspects, genetic, pathology, and molecular pathomechanisms. Biochim Biophys Acta BBA - Mol Basis Dis $\underline{1852}, 594-606$

Metzemaekers M, Vanheule V, Janssens R, Struyf S, Proost P (2018): overview of the mechanisms that may contribute to the non-redundant activities of interferon-inducible CXC chemokine receptor 3 ligands. Front Immunol 8:1970. 
Molyvdas A, Georgopoulou U, Lazaridis N, Hytiroglou P, Dimitriadis A, Foka P, Vassiliadis T, Loli G, Phillipidis A, Zebekakis P, et al. (2018): the role of the NLRP3 inflammasome and the activation of IL-1 $\beta$ in the pathogenesis of chronic viral hepatic inflammation. Cytokine 110: 389-396

Naschberger E, Geißdörfer W, Bogdan C, Tripal P, Kremmer E, Stürzl M, Britzen-Laurent $N(2017)$ : processing and secretion of guanylate binding protein-1 depend on inflammatory caspase activity. J Cell Mol Med 21, 1954-1966

Ozaki E, Campbell M, Doyle SL (2015): targeting the NLRP3 inflammasome in chronic inflammatory diseases: current perspectives. J Inflamm Res $\underline{8}, 15-27$

Pluk $\mathrm{H}$, van Hoeve BJA, van Dooren SHJ, Stammen-Vogelzangs J, van der Heijden A, Schelhaas HJ, Verbeek MM, Badrising UA, Arnardottir S, Gheorghe K et al. (2013): autoantibodies to cytosolic 5'-nucleotidase $1 \mathrm{~A}$ in inclusion body myositis. Ann Neurol $\underline{73}, 397-407$

Rawat R, Cohen TV, Ampong B, Francia D, Henriques-Pons A, Hoffman EP, Nagaraju K (2010): inflammasome up-regulation and activation in dysferlin-deficient skeletal muscle. Am J Pathol 176, 2891-2900

Rayavarapu S, Coley W, Kinder TB, Nagaraju K (2013): idiopathic inflammatory myopathies: pathogenic mechanisms of muscle weakness. Skelet Muscle $\underline{3}, 13$

Robbins GR, Wen H, Ting JP-Y (2014): inflammasomes and metabolic disorders: old genes in modern diseases. Mol Cell $\underline{54}, 297-308$

Rose MR et al. (2013): 188th ENMC International Workshop: inclusion body myositis, 2-4 December 2011, Naarden, The Netherlands. Neuromuscul Disord NMD 23, 1044 1055

Salajegheh M, Lam T, Greenberg SA (2011): autoantibodies against a 43 KDa muscle protein in inclusion body myositis. PloS One $\underline{6}$, e20266

Schmidt J (2018): Current Classification and Management of Inflammatory Myopathies. J Neuromuscul Dis $\underline{5}, 109-129$

Schmidt J, Dalakas MC (2013): Inclusion body myositis: from immunopathology and degenerative mechanisms to treatment perspectives. Expert Rev Clin Immunol $\underline{9}$, $1125-1133$

Schmidt J, Rakocevic G, Raju R, Dalakas MC (2004): Upregulated inducible co-stimulator (ICOS) and ICOS-ligand in inclusion body myositis muscle: significance for CD8+ T cell cytotoxicity. Brain J Neurol 127, 1182-1190

Schmidt J, Barthel K, Wrede A, Salajegheh M, Bähr M, Dalakas MC (2008): interrelation of inflammation and APP in SIBM: IL-1 beta induces accumulation of beta-amyloid in skeletal muscle. Brain J Neurol 131, 1228-1240

Schmidt K, Schmidt J (2017): inclusion body myositis: advancements in diagnosis, pathomechanisms, and treatment. Curr Opin Rheumatol 29, 632-638

Schmidt K, Wienken M, Keller CW, Balcarek P, Münz C, Schmidt J (2017): IL-1ß-induced accumulation of amyloid: macroautophagy in skeletal muscle depends on ERK. Mediators Inflamm 2017:5470831 
Schoser B (2009): inflammatorische myopathien. Z Für Rheumatol $\underline{68}, 665$

Shenoy AR, Wellington DA, Kumar P, Kassa H, Booth CJ, Cresswell P, MacMicking JD (2012): GBP5 promotes NLRP3 inflammasome assembly and immunity in mammals. Science $\underline{336}, 481-485$

Vazirinejad R, Ahmadi Z, Arababadi MK, Hassanshahi G, Kennedy D (2014): the biological functions, structure and sources of CXCL10 and its outstanding part in the pathophysiology of Multiple Sclerosis. Neuroimmunomodulation 21, 322-330

Vilaysane A, Chun J, Seamone ME, Wang W, Chin R, Hirota S, Li Y, Clark SA, Tschopp J, Trpkov K, et al. (2010): the NLRP3 inflammasome promotes renal inflammation and contributes to CKD. J Am Soc Nephrol JASN 21, 1732-1744

Wehner M, Herrmann C (2010): biochemical properties of the human guanylate binding protein 5 and a tumor-specific truncated splice variant. FEBS $\mathrm{J} \underline{277}, 1597-1605$

Yao Y, Qian Y (2013): expression regulation and function of NLRC5. Protein Cell $\underline{4}, 168-$ 175

Yin X, Han GC, Jiang XW, Shi Q, Pu CQ (2016): increased expression of the NOD-like receptor family, pyrin domain containing 3 inflammasome in dermatomyositis and polymyositis is a potential contributor to their pathogenesis. Chin Med $\mathrm{J}$ (Engl) 129, 1047-1052 


\section{Danksagung}

Mein Dank gilt meinem Doktorvater Prof. Dr. Jens Schmidt für die Projektidee und die Möglichkeit frei daran arbeiten und mitgestalten zu können. Die allzeit bestehende Ansprechbereitschaft und Unterstützung haben bei der Entstehung dieser Arbeit größten Anteil.

Des Weiteren möchte ich mich bei der gesamten Arbeitsgemeinschaft Muskelimmunbiologie und insbesondere bei Herrn Dr. Karsten Schmidt für die Unterstützung und den regelmäßigen Austausch im Fachlichen und Technischen bedanken.

Mein besonderer Dank gilt Frau Iris Iben und Frau Adriane Stas, die mit ihrer fachlichen Kompetenz, Hilfsbereitschaft und Engagement einen großen Anteil an der erfolgreichen Durchführung der Experimente und des gesamten Projektes haben. 


\section{Lebenslauf}

Mein Name ist Imke Bertram. Am 07.06.1991 wurde ich als Tochter und zweites Kind von Frau Sieglinde Bertram (geb. Fehlig) und Herrn Christian Bertram in Bad Gandersheim geboren. Mein Bruder ist Eike Christian Bertram.

Aufgewachsen im ländlichen Raum Südniedersachsens erlangte ich im Juni 2010 meine Allgemeine Hochschulreife am Roswitha-Gymnasium Bad Gandersheim. Nach einem Semester Biochemie an der Gottfried Wilhelm Leibniz-Universität Hannover im Wintersemester 2010/2011 wechselte ich zum Sommersemester 2011 an die Universität zu Köln und begann dort das Humanmedizinstudium. Nach Abschluss des vorklinischen Abschnittes mit bestandener Physikumsprüfung wechselte ich zur Fortführung des Studiums zum Sommersemester 2013 an die Georg-August-Universität Göttingen. Im Rahmen des Studiums legte ich im Oktober 2016 das schriftliche Staatsexamen und im Dezember 2017 das mündliche Staatsexamen erfolgreich ab.

Im Jahr 2014 begann ich in der Arbeitsgruppe für Muskelimmunbiologie bei Prof. Dr. med. Jens Schmidt diese Doktorarbeit.

Seit August 2018 bin ich als Assistenzärztin in der Klinik für Kinder- und Jugendheilkunde des Klinikums Kassel tätig. 